\title{
Maternal Stress and Pregnancy Outcomes
}

\section{Evidence from a natural experiment: the 2004 Madrid Train Bombings}

\author{
Cozzani Marco \\ European University Institute \\ marco.cozzani@eui.eu
}

\author{
Triventi Moris \\ University of Trento \\ moris.triventi@unitn.it
}

\author{
Bernardi Fabrizio \\ European University Institute \\ fabrizio.bernardi@eui.eu
}

Corresponding author: Marco Cozzani, marco.cozzani@eui.eu. Department of Political and Social Science, European University Institute, Badia Fiesolana, Via dei Roccettini 9, I-50014, San Domenico di Fiesole (Italy).

\begin{abstract}
Previous studies have shown that the reproduction of social background inequality start at births and even in the womb. We advance the understanding of the inequality in early life outcomes by analyzing whether prenatal stress affects prematurity and low birth weight and how this effect varies by parental socio-economic status. To address the endogeneity of prenatal stress and pregnancy outcomes we use a natural experiment and consider the 2004 Madrid train bombings as an exogenous source of stress. Compared to other natural experiments used in prior research, our design has higher credibility and enable us to exclude biases due to various confounders. We analyze administrative data referring to the whole population of newborns in Spain and use a difference-in-differences design with a synthetic control approach. We find that children exposed to the Madrid bombing had a higher risk of prematurity and low birth weight, and that this detrimental effect is concentrated among low-SES offspring. We discuss four possible mechanisms to explain this heterogeneity and rely on findings of previous research and on information from additional data to test their plausibility. In the conclusions we highlight the broader implications of our findings for the reproduction of social inequalities across generations.
\end{abstract}

Keywords: maternal stress, natural experiment, parental response, birth endowments, difference-indifferences, synthetic control 


\section{Introduction}

Previous studies have shown that the inequality of opportunity begins at birth and even in womb (Almond, Currie, \& Duque, 2017; Conley \& Bennett, 2000; Härkönen, Kaymakçalan, Mäki, \& Taanila, 2012; Torche, 2011; Torche \& Villarreal, 2014). Previous studies have also documented that exposure to prenatal stress increases the risk of adverse pregnancy outcomes (Aizer, Stroud, \& Buka, 2016; Almond et al., 2017; Brown, 2018; Persson \& Rossin-Slater, 2018; Torche, 2011; Torche \& Villarreal, 2014) that are crucial determinants of socio-economic and health outcomes later in life (Black, Devereux, \& Salvanes, 2007; Conley \& Bennett, 2001; Heckman, 2007; Torche, 2018). Exposure to maternal stress in the womb may then be an important biological mechanism of intergenerational transmission of socio-economic status (SES) and poverty (McEwen \& McEwen, 2017).

In this article we advance the understanding of the inequality in early life outcomes by analyzing whether prenatal stress affects prematurity and low birth weight (LBW) and how this effect varies by parental socio-economic status. To address the endogeneity of prenatal stress and pregnancy outcomes we use a natural experiment and consider the 2004 Madrid train bombings as an exogenous source of stress. The 2004 Madrid train bombings was carried out by an Al-Qaeda linked terrorist cell and was the deadliest terrorist attack in the history of Europe since 1988, with 193 people killed and about 2,000 injured.

We focus on two research questions. First, did exposure to stress associated with the train bombings lead to an increase in the risk of prematurity and LBW for children of women who were pregnant in Madrid at the time of the terrorist attack in March 2004? Second, did the effect vary by parental socio-economic status (SES)? To answer these questions, we use data for the universe of births in Spain in the years between 2000 and 2005 and employ a difference-in-differences design combined with a synthetic control approach (Abadie, Diamond, \& Hainmueller, 2010; Abadie \& Gardeazabal, 2003), following a similar strategy to Torche and Sirois (2018). We compare the risk 
of prematurity and LBW of those who were in utero in Madrid at the time of the bombing with those who were born before in Madrid and in a comparable synthetic control province.

A number of recent studies have similarly relied on natural experiments such as earthquakes, wars, discriminatory policies, bereavement, sports events and terrorist attacks to estimate the causal impact of prenatal stress on children's outcomes at birth (Black, Devereux, \& Salvanes, 2016; Currie \& Rossin-Slater, 2013; Duncan, Mansour, \& Rees, 2017; Eskenazi, Marks, Catalano, Bruckner, \& Toniolo, 2007; Kim, Carruthers, \& Harris, 2017; Persson \& Rossin-Slater, 2018; Torche, 2011; Torche \& Sirois, 2018; Torche \& Villarreal, 2014). Our article makes two main contributions to the existing research. First, using the Madrid train bombings as an exogenous shock we overcome likely biases of previous studies that used natural experiments to study the effect of prenatal stress on pregnancy outcomes. We will argue that in our natural experiment has higher plausibility and credibility compared to previous ones (Dunning 2012). Second, when compared to previous studies (Sherrieb \& Norris, 2013) we focus on the heterogeneity of the effect of prenatal maternal stress on birth outcomes, and we show that negative consequences induced by the Madrid bombing are concentrated among low-SES mothers exposed to stress in the second trimester. We also discuss four possible mechanisms underlying such finding. These are: differential exposure, selective survival, differential sensitivity, and stratified parental response by SES. We collected additional information and refer to results of prior studies to evaluate the plausibility of each these four mechanisms.

The article is structured as follows. In the next two sections, we discuss the relationship between terrorist attacks, maternal stress and birth outcomes, and the possible heterogeneity of this relationship by SES. We then describe the salient features of the 2004 Madrid train bombings in the third section. The fourth section is devoted to presenting the data, variables, and analytical strategy. We then present the results of our analyses and discuss their implications in the concluding sections. 


\section{Terrorist Attacks, Stress, and Pregnancy Outcomes}

Terrorist attacks are traumatic events associated with the spread of stress and fear in the population, as well as with the onset of mental disorders (Becker \& Rubinstein, 2004). Early research found that individuals involved in the Oklahoma City bombing in 1995 showed high incidence of post-traumatic stress disorder (PTSD) and depression, with the rate of incidence for women being twice that of men (North et al., 1999). Moreover, it is not only individuals directly involved in terrorist attacks who may start to suffer from mental disorders, but also those who live near the location of an attack. In the aftermath of 9/11, two studies estimated that the prevalence of PTSD was substantially higher in the New York City metropolitan area than in other parts of the US (Galea et al., 2002; Schlenger et al., 2002). Similarly to this research on New York City, a study investigated the prevalence of PTSD and depression disorder in the Madrid population in the two months following the train bombings. The authors found an increase in the onset of PTSD among individuals living in areas close to where the bombings happened comparable to that found in New York City, and also observed an increase in event-related depression (Miguel-Tobal et al., 2006). This evidence therefore suggests that a major terrorist attack may increase stress levels in the population, especially for individuals who are living closer to the event.

Previous research has identified physiological mechanisms that link maternal exposure to stress and fetal development (McLean et al., 1995). Exposure to an environmental threat triggers the activation of the hypothalamic-pituitary-axis, and the subsequent release of corticotropin-releasing hormone (CRH), adrenocorticotropin hormone and cortisol (Dickerson \& Kemeny, 2004; Dunkel Schetter, 2011; Hobel, Goldstein, \& Barrett, 2008; Mancuso, Schetter, Rini, Roesch, \& Hobel, 2004). In pregnant women, high levels of these hormones, and especially of CRH during the first and second trimester of gestation, have been shown to be associated with preterm delivery (Holzman, Jetton, Siler-Khodr, Fisher, \& Rip, 2001). More specifically, it has been argued that - together with other biological clocks - there is a placental clock that is regulated by the levels of CRH hormone. High 
levels of CRH at even 16-20 weeks of gestation may set the placenta on course for a preterm delivery (McLean et al., 1995). Moreover, gestational length is one of the determinants of birth weight, and a short gestation increases the chances of low birth weight deliveries (Hobel et al., 2008; Kiserud et al., 2017).

\section{Heterogeneous effects of terrorist attacks by SES? Four potential mechanisms}

Even though the neuro-endocrine mechanism has been extensively adopted to explain how an exogenous stressful event may affect pregnancy outcomes, little is known about whether the effect of maternal stress on pregnancy outcomes is uniform in the population or heterogenous across socioeconomic strata. There are four possible moderating mechanisms of SES: differential exposure, selective survival, differential sensitivity, and stratified parental response by SES.

First, differential exposure might come about because some social groups are over-represented in the place where the stressful event occurs. An associated mechanism is stress diffusion through the social networks of individuals. Through homophily, low-SES individuals tend to have friends and relatives who are low-SES as well (e.g. McPherson, Smith-Lovin, and Cook (2001)). Consequently, if low-SES individuals were more likely to be directly affected by the event generating stress (for instance because they were more likely to use the morning-rush commuter trains in Madrid when the train bombings happened), it is more probable that their relatives and friends suffered the highest attack-related stress, increasing the exposure to stress in the low-SES group.

Another possible mechanism is different sensitivity to stress among mothers (Torche, 2018). Since stress is unevenly distributed along the socio-economic scale, and mothers face different level of stress in their everyday lives, exposure to an acute stressor may lead to different outcomes. If an acute stressor accentuates pre-existing stress, low-SES mothers who are more exposed to socioeconomic difficulties and chronic stress should be the ones most affected (Turner \& Avison, 2003). However, an alternative scenario is also theoretically possible: mothers more exposed to socio- 
economic difficulties and stress in their everyday lives may have developed more resilience to stress, and an acute stressor might not be particularly salient for them (Feder, Nestler, \& Charney, 2009).

A third mechanism is selective survival. Estimations of an exogenous stressor on birth outcomes are usually made on live births. However, if an in utero shock increases the chances of miscarry weak fetuses, the live births may be positively selected. The real effect of the stressor would then be underestimated (Bharadwaj, Løken, \& Neilson, 2013; E. M. Liu, Liu, \& Tseng, 2015). If selective survival differs across social strata, this mechanism may account for a heterogenous effect of the shock on live birth outcomes. If high SES mothers are more likely to miscarriage weak fetuses when exposed to stress because, for instance, they are on average older when becoming pregnant (de La Rochebrochard \& Thonneau, 2002), then the increase in LBW induce by the external shock would only be observed among low SES mothers who are more likely to bring the pregnancy to an end.

The fourth mechanism refers to heterogeneous parental responses to an exogenous stressor. Parents may engage in prenatal investments aimed at influencing their child's fetal health. A vast literature has investigated how parents respond to child endowments - that is, how parents perceive their child's endowments and take action intended to enhance them (Almond \& Mazumder, 2013; Grätz \& Torche, 2016; Hsin \& Felfe, 2014). This literature has been concerned with whether parents reinforce (Behrman, Pollak, \& Taubman, 1982) or compensate (Becker \& Tomes, 1976) for initial differences in child endowments. From this initial research, a new strand is investigating whether parental investments are socially stratified, as high-SES parents may be more likely to compensate, and low-SES parents may be more likely to reinforce for initial endowment disparities under resource constraints (Bernardi, 2014; Conley, 2008). Although this research usually assumes that parents react to how a child is endowed after birth - that is, when endowments are visible - parents might also be able to recognize that a health insult happened to the fetus, and act (or not) to reduce the effect of stress on child's development in utero. For example, parental access to prenatal care may be particular relevant. Torche and Villarreal (2014) found that exposure to violence led to increased birth weight, 
especially among low-SES. And their analysis on the underlying mechanism attributed this gain to the increased access to this pro-health behavior.

Conversely, the stress generated by the bombing may not directly affect fetal health, but it may induce detrimental physical conditions and behaviors (Persson \& Rossin-Slater, 2018). For instance, mothers may see their sleeping patterns disrupted, experience cardiovascular anomalies, change eating habits, re-start smoking, increase the number of cigarettes smoked or alcohol ingested, thus harming fetal health. However, it is possible that mothers do not engage in these behaviors equally, particularly since it is well-established that low-SES individuals are more likely to engage in unhealthy behavior as a response to negative life events (Pampel, Krueger, \& Denney, 2010), and low-SES mothers are more likely to smoke in pregnancy in Spain (Delgado et al., 2012). Consequently, if the bombing induced behaviors or conditions detrimental for fetal health, the effect is most likely to be observed among low-SES.

\section{The 2004 Madrid Train Bombings}

During the peak of rush hour at 7.40 am on March $11^{\text {th }}, 2004$, an Al-Qaeda linked terrorist cell exploded ten bombs simultaneously across four different commuter trains in Madrid. The explosions killed 193 people and around 2,000 were injured. The attacks occurred three days before the March $14^{\text {th }}$ general election that was unexpectedly won by the socialist party of José Zapatero (Montalvo, 2011). In the aftermath of the bombings there was uncertainty over their origins, with the government initially pointing to the Basque Terrorist organization ETA as being responsible for the massacre. On March $12^{\text {th }}$ mass demonstrations in solidarity against terrorism took place in Madrid with more than two million participants. On the $13^{\text {th }}$, thousands of people took to the streets of Madrid again. Spontaneous protest accused the right-wing government of manipulating information about the authorship of the bombing in order to elude responsibility for having involved the country in the Iraq 
war. While demonstrations against terrorism and against the government took place in all major cities in Spain, the level of political and social turmoil was highest in Madrid, particularly on March $13^{\text {th }}$.

We use the Madrid train bombings to estimate the causal effect of prenatal maternal stress on pregnancy outcomes. The logic and assumptions of our research design are illustrated in the DAG in Figure 1 below.

[Figure 1 about here]

The core idea of our design is that the terrorist attack produced more stress among pregnant women who were more proximately exposed to it, i.e. those living in the Madrid area compared to the rest of Spain, and enough stress to affect birth outcomes. The arrow $a$ and $b$ are dashed because we cannot observe them. In our analysis, we then estimate the arrow $c$, the reduced form effect of the exposure to the bombing on birth outcomes.

For such estimate to provide a valid estimate of stress on birth outcomes, we have to provide evidence that the terrorist attack was a major source of stress among the population living in Madrid (the relevance assumption). As discussed in the previous section, studies conducted in the aftermath of terrorist attacks, such as the 9/11 in New York and also the 11-M in Madrid, documented an increase in PTSD among those living in the city and area affected by episode of violence (Galea et al., 2002; Miguel-Tobal et al., 2006). The plausibility of the relevance assumption seems then to be high. We have, also, to exclude that the terrorist attack (A) affects birth outcomes (Y) through alternative pathways $(\mathrm{Z})$, the exclusion restriction assumption; and to exclude that the terrorist attack (A) does not share common causes (U) with (Y) birth outcomes - the ignorability assumption. Further, Dunning (2012) suggests three dimensions to evaluate natural experiment: plausibility of as if at random, credibility and substantive relevance. In the following we consider the former two 
dimensions and discuss the latter in the conclusions when we discuss on the difference between acute and chronic stress.

Although the terrorists deliberately attacked Madrid in the sensible days preceding the general elections, the attack was sudden and unpredicted, as also intelligence services had very limited and uncertain information on the probability of such an attack (Jordán \& Horsburgh, 2006). Given this unpredictable and episodic nature of the attack, we study only offspring that were already in the womb at the time of the bombings, which fertility decisions were taken before of the event, making anticipative behaviors strongly unlikely. This implies that being pregnant at the time of the bombing compared to having delivered just before it, is ultimately random. We can then exclude a possible confounder of the relationship between the bombing and birth outcomes, namely the probability of an attack (u1) and the consequent selective fertility behavior (u2). Individuals may in fact adapt their fertility behavior to the social context in which they live. For instance, they might decide not to become pregnant if there is a risk of war or if they live in an area where violence is likely to happen, and this adaptive response may also be socially stratified (Brown, 2018; Torche \& Villarreal, 2014).

With regard to the credibility of this natural experiment, we have to rule out possible alternative causal paths through which the bombings might have affected pregnancy outcomes, such as the paths $\mathrm{X} \rightarrow \mathrm{Zi} \rightarrow \mathrm{Y}$ with $i$ from 1 to 7 , in the DAG of Figure 1. Although the attack involved the public transportation infrastructure, there were not long-lasting interruptions in public transport which may have limited access to food or care. An emergency plan was adopted already on the $11^{\text {th }}$ of March, with shuttle services creating additional connections between the affected lines, and on the $12^{\text {th }}$ the commuting infrastructure was functioning normally ${ }^{1}$. Second, there was no destruction involving housing or hydric infrastructure, and no evidence of out-migration, as the population in the autonomous community of Madrid grew steadily in the early $2000 \mathrm{~s}^{2}$. This distinguishes our case from what may happen as a consequence of an earthquake, thus excluding displacement, forced outmigration, malnutrition, or water contamination as possible pathways that affect pregnancy outcomes. 
Moreover, since no pollution cloud was generated - for example, in contrast to the $9 / 11$ attacks in the United States - we can rule out the possibility that attack-related pollution fallout might have affected pregnancy outcomes (Currie \& Schwandt, 2015). Finally, the possible role played by the unexpected election results hold just three days after the terrorist attacks deserved a more detailed discussion that we provide in the results section.

All in all, the features just discussed give support to the exclusion restriction and ignorability assumption and adds to the credibility and plausibility of the as if random of the Madrid bombing as a natural experiment (Dunning 2012), compared to other natural experiments used in previous studies to identify the effect of stress on birth outcomes.

\section{Data, Variables, and Analytical Strategy}

Data

We estimate the effect of the Madrid train bombings on pregnancy outcomes drawing on Spanish register data from the Population Movement Statistics provided by the Spanish National Statistical Office (Instituto Nacional de Estadistica) ${ }^{3}$. These are administrative data that refer to the whole population of newborns. Parents are required by the Spanish law to register their child in the civil register within 30 days from birth, with the average time being 9 days (Juárez, Alonso Ortíz, RamiroFariñas, \& Bolúmar, 2012) ${ }^{4}$. When parents register their child, they are also required by law to fill in a questionnaire that includes information on the place of birth, gestational age, anthropometric information on the newborn, and their occupations. We consider children conceived between January 2000 and February 2005. In the following analyses, we include only singleton births. We have then a maximum of 2,171,103 observations for the analysis of prematurity and 2,068,916 observations for the analysis of LBW. The number of observations changes across our dependent variables as there are missing observations for LBW (more below). 


\section{Variables}

In line with previous studies, we define our dependent variables, low birth weight (LBW) and prematurity, as dummy variables (Currie \& Rossin-Slater, 2013; Duncan et al., 2017; Kim et al., 2017; Torche, 2011). Prematurity takes value zero for children born at or after the $37^{\text {th }}$ week of gestation, and value one for children born at or before 36 weeks of gestation. This variable does not have any missing value as the Spanish statistical office imputed the cases where no information for gestational age in week was available (about 12\%). When we use gestational age in weeks for counting backward from the month of birth to estimate the month of conception, we impute the cases with the missing number of weeks of gestation using the $36^{\text {th }}$ and $37^{\text {th }}$ week of gestation threshold based on the information on prematurity. It is nonetheless worth noticing that our results are not affected if we exclude these cases with missing information on gestational age in weeks from the analysis. Table A2.1 in the online appendix reports the distribution of the missing values on gestational age across parental SES.

For the LBW variable, zero indicates newborns weighing at least 2,500 grams (included), and one the newborns weighing less than 2,500 (excluded) grams. Some studies highlighted how the birth weight variable may stack at the 2499/2500 grams threshold (Brown, 2018); thus we repeated the analyses considering the 2500 grams category as LBW and results are consistent. This variable has around $5 \%$ of missing values. Missing cases do not correlate with any relevant covariate, and Table A2.2 in the online appendix reports the distribution of missing cases across parental SES categories ${ }^{5}$.

Our key stratifying variable is parental SES, which is derived from information on the main occupation of the mother and the father ${ }^{6}$. In the years covered in our study, parents' occupation is provided by the Population Movement Statistics using 12 categories from ISCO 68: (1) Professionals, technicians and associate professionals; (2) Managers and legislators; (3) Clerical support workers; (4) Salesman and shop owners; (5) Sales and services elementary occupations; (6) Agricultural, forestry and fishery workers; (7) Production workers, trade workers, plant and machine operators (8) 
Army; (9) Students; (10) Housewives; (11) Retired; (12) No information. We recoded the 12 categories in three broad groups where "high SES" includes category 1 and 2; "medium SES" includes categories 3 and 4; and "low SES" consists of categories 5, 6, and 7. We validate our classification by using secondary data on income levels from a different survey ${ }^{7}$. We then construct the parental SES variable as the highest category between the two parents. In the general analyses (where we do not explore SES heterogeneity) we also include two other categories for inactive individuals $\left(9,10\right.$, and 11) and individuals with no information or belonging to armed force $(8,12){ }^{8}$ We have also replicated the analysis constructing the SES based only on the information on mothers' occupation and the results do not change (results available upon request).

In the analyses, we control for month of conception and year of conception, in order to rule out seasonal variations in pregnancy outcomes (Currie \& Schwandt, 2013). We also include as controls potential socio-demographic confounders: (1) four categories for the mother's age, as there is a complex relation between maternal age and birth outcomes (Goisis, Remes, Barclay, Martikainen, \& Myrskylä, 2017); (2) sex of the newborn; (3) number of children the mother had at the time of delivery; (4) mother's marital status; (4) whether the mother is not Spanish, as non-Spanish mother are shown to deliver heavier children (Cebolla-Boado \& Salazar, 2016).

\section{Treatment identification}

We identify children exposed to the terrorist attack geographically and by trimesters of conception. Geographically, we consider as treated those children who are born in the province of Madrid in the nine months after the terrorist attack (i.e. who were in utero when the attack occurred). This identification relies on the assumption that mothers who delivered their children in Madrid between April 2004 and December 2004 were also living in Madrid in March 2004. This assumption seems reasonable given the extremely low internal mobility rate in Spain (L. Q. Liu, 2018). 
A second assumption is that mothers living in proximity to the terrorist attacks are more likely to suffer from its psychological consequences. The literature we reviewed in a previous section shows that individuals living closer to a traumatic event such as a terrorist attack reported a higher incidence of psychological conditions (depression, PTSD) than the rest of the population (Miguel-Tobal et al., 2006). Therefore, we assume pregnant women living in proximity to the terrorist attacks have more likely perceived it as a concrete threat to their lives, or they have more likely feared the involvement of their relatives and acquaintances, and consequently have experienced higher levels of stress that may be harmful for their fetus' development. We thus expect the effect of the exposure to the terrorist attacks to be more acute for mothers and their in utero children in the province of Madrid compared to mothers living and their in utero children in the other 49 Spanish provinces. We build our variable using the administrative information regarding the newborn's addition to the provincial civil register, which has no missing values and does not suffer from the bias that the self-reported information on the mother's municipality of residence has 9 .

We identify the trimester of pregnancy at the time of the bombing by counting forward from the month of conception, which allows us to resolve endogeneity problems when estimating the effect of the exposure on prematurity (Currie \& Rossin-Slater, 2013). We estimate the month of conception by assuming that everyone is born on the $15^{\text {th }}$ day of their month of birth and by subtracting from it the weeks of gestation ${ }^{10}$.

\section{Control group}

We apply a synthetic control method, which provides a systematic way to choose comparison units in comparative case studies (Abadie et al. 2010). Instead of relying on specific and ad-hoc selected control units, the comparison unit in the synthetic control method is selected as the weighted average of all potential comparison units that best resembles the characteristics of the case of interest (Abadie et al. 2015). In our analysis, we define a synthetic control (SC) province that best resemble the pre- 
treatment Madrid province (Abadie et al., 2010; Abadie \& Gardeazabal, 2003). We use this procedure to generate province-level weights to use in the individual level analysis, and to reduce arbitrariness in the decision of the control group (Torche \& Sirois, 2018). More precisely, we construct a specific synthetic control province for each of our birth outcome (LBW and prematurity).

To construct the synthetic control provinces, we first create a province-by-trimester dataset with 50 provinces by 20 trimesters of conception (i.e. points in time) ${ }^{11}$. We defined pre-treatment time points as trimesters that match the trimesters of conception which lead to first, second and third trimester of pregnancy at the time the bombing, as illustrated in Table 1. Of these time points: 13 correspond to pregnancies concluded before the attack, three trimesters correspond to pregnancies that were exposed to the bombing, and four trimesters correspond to conceptions after the bombing.

[Table 1 about here]

For each province and time point (as described in Table 1), we aggregate information from the individual data on rates of LBW, prematurity and other variables such as: share of unmarried mothers, the share of non-Spanish mothers, maternal age at birth; share of high/medium/low SES families; trimester province-specific number of births. We then generate the synthetic control province by matching Madrid with the rest of Spanish provinces on the pre-treatment trends in the variables we mentioned above, together with the trends of the outcome variable to soak up heterogeneity (Abadie et al., 2010). This procedure generates two sets of weights, one for LBW and one for prematurity, that we then apply in the individual level analysis to define the control groups (Table A1.1).

The two sets of weights for LWB and prematurity generated by the procedure are different. There are two explanations for this result. First, even though our two outcomes - LBW and prematurity - are intuitively highly correlated, their observed correlation is far from perfect and 
around 0.5 . One has to consider that prematurity is a cause of LBW, but not the only one. Another cause is fetal growth, which is related to the gestational-age specific growth of the fetus. Prematurity and fetal growth have different causes and consequences (Torche \& Conley, 2016).

Second, our synthetic control specification strategy matches on all pre-treatment values of the outcome (LBW or prematurity). This choice makes the trends in the outcomes the most important predictors in the generation of the synthetic control province, and this strategy is also likely to increase the number of weights allocated in the donor pool respect to specification using less pre-treatment outcomes (Ferman, Pinto, \& Possebom, 2017). We decided to include all pre-treatment outcomes in the matching algorithm to define the synthetic control province because the most important determinants at the treatment level (province) of birth outcomes are most likely to be unobserved (i.e. pollution, flu). Moreover, we are interested in estimating a sudden and transitory shock instead of the consequences of a policy intervention with long-term effects. Hence, this case is substantially different from synthetic control applications investigating economic outcomes of regions/countries, where factors determining these performances (i.e. GDP) are more likely observable.

The decision of whether or not to include all pre-treatment outcomes in the generation of the synthetic control provinces is somewhat controversial. Some authors have recently warned against the adoption of all pre-treatment outcomes in the definition of synthetic control on the basis that they may make other covariates less relevant in the generation of the synthetic control (Kaul, Klößner, Pfeifer, \& Schieler, 2015). In a recent article, Torche \& Sirois (2018) addressed this issue by using only one pre-treatment average value of the outcome as matching variable. Following Torche $\&$ Sirois (2018) we computed a synthetic control with only the pre-treatment average value of the outcome together with other covariates and find that the results are fully consistent with those presented in the article $^{11}$. In addition, when we define the synthetic control with only the average of the pre-treatment outcome, the synthetic control weights are much more similar between the outcomes (Table A1.2). 
In online appendix 1, we use an alternative specification of the synthetic control province, and we also provide results that are not based on synthetic control provinces, comparing our treatment group (children born in Madrid) with the aggregate of all Spanish provinces. The results of the sensitivity analyses show that our findings are highly robust to alternative definitions of the control group.

\section{Analytical Strategy}

We apply a difference-in-differences (DID) estimator. In the general analysis, we consider children conceived from January 2000 to right before the attack (February 2004 - column 1 to 4 of Table 1). We divide them into four groups: (1) children born before the attack ( $t b)$; (2) children exposed in the third trimester of gestation $(t 3)$; (3) children exposed in the second trimester of gestation $(t 2) ;(4)$ children exposed in the first trimester of gestation $(t 1)$.

We have then three DID estimators referring to each exposed trimester of gestation compared to the period before the attack. Formally:

$$
\begin{aligned}
& \text { (1) } D I D_{t 1}=\left(Y_{t 1}^{g m}-Y_{t b}^{g m}\right)-\left(Y_{t 1}^{g c}-Y_{t b}^{g c}\right) \\
& \text { (2) } D I D_{t 2}=\left(Y_{t 2}^{g m}-Y_{t b}^{g m}\right)-\left(Y_{t 2}^{g c}-Y_{t b}^{g c}\right) \\
& \text { (3) } D I D_{t 3}=\left(Y_{t 3}^{g m}-Y_{t b}^{g m}\right)-\left(Y_{t 3}^{g c}-Y_{t b}^{g c}\right)
\end{aligned}
$$

In equation (1) $D I D_{t 1}$ represents the difference-in-differences estimator for the $1^{\text {st }}$ trimester of pregnancy and the period before the bombing, $Y_{t 1}^{g m}$ represents the average pregnancy outcome for the province of Madrid $g m$ at the first trimester of exposure $t 1, Y_{t b}^{g m}$ refers to the same outcome in the province of Madrid $g m$ for those born before the attack $t b ; Y_{t 1}^{g c}$ represents the average pregnancy 
outcome for the control group $(g c)$ in the first trimester, whereas $Y_{t b}^{g c}$ is the same outcome for those born before the attack $t b$ in the control group $g c$. Equations (2) and (3) adopt an analogous notation.

The DID parameters are estimated using linear probability models (LPM) with years and month of conception fixed effects and standard errors clustered at the provincial level (Bertrand, Duflo, \& Mullainathan, 2004). Our model specification includes an interaction term between the dummy variable $\left(g_{k}\right)$ that distinguishes the province of Madrid and the synthetic control province, and the four time periods $\left(t_{k}\right)$ that refer to children born before the attack, and children who were in the $1^{\text {st }}, 2^{\text {nd }}$ and $3^{\text {rd }}$ trimester of gestation at the time of the attack. It also includes a vector $\boldsymbol{Z}$ of control variables and fixed effect for the month (M) and year (Y) of conception. The model is specified as follows:

(4) $Y_{i k t m t}=a+\beta_{1}\left(G_{k}\right)+\beta_{2}\left(T_{t}\right)+\beta_{3}\left(G_{k} \times T_{t}\right)+\beta_{4}\left(M_{m}\right)+\beta_{5}\left(Y_{y}\right)+\left(\boldsymbol{Z}_{\text {iktmy }}\right) \boldsymbol{\beta}_{6}+\varepsilon_{i k t y m y}$

Where $i$ is an infant, $k$ is the province of birth (Madrid versus synthetic control), $t$ distinguishes the time period, $m$ and $y$ are the month and year of conception. The coefficients $\beta_{3}$ for the interaction $\left(G_{k} \times T_{t}\right)$ represents the estimators specified in the DID equations (1) to (3). $\beta_{4}\left(M_{i}\right)$ and $\beta_{5}\left(Y_{I}\right)$ are month and year of conception fixed effects. In order to analyze the heterogeneity by parental SES, we estimate three separate models equivalent to model (4) above for high-SES, medium-SES, and low-SES mothers ${ }^{12}$.

Finally, although our estimates refer to the entire population of births in Spain for the period considered, we follow common practice in reporting statistical significance levels for the coefficients estimated by our models ${ }^{13}$. Nonetheless, in commenting on the results we attribute greater relevance to substantive significance of coefficients and contrast their size to the effects of stress on pregnancy outcomes found by comparable studies. 


\section{Empirical findings}

Exposure to the Madrid bombings and pregnancy outcomes

In Table 2 we present the results of the general analysis obtained from LPMs: in Model 1 the dependent variable is the probability of being born prematurely, while Model 2 that of LBW. The LPMs use synthetic control provinces for each outcome, and they have standard errors clustered at provincial level.

The interaction term between the dummies for the trimester of gestation and the dummy for Madrid province (MP) reports the DID estimator for the exposure to stress associated with the March 2004 bombings in Madrid. In Model 1, the probability of being born prematurely is largest for children exposed to the bombing during the second trimester of gestation. Their probability of being born prematurely is 1.4 percentage points larger than those in the control group ( 8.1 per cent compared to 6.7 per cent, i.e. about a 20 per cent increase in relative terms). No effect is found for the first and third trimester of pregnancy. We find a very similar pattern in Model 2: the exposure to the bombing in the second trimester of gestation increases the probability of LBW by 1.1 percentage points (5.7 per cent compared to 4.6 per cent, i.e. about a $20 \%$ increase). Instead, no or very small effects are found for those exposed in the first and third trimester of pregnancy.

To sum up, in line with theoretical accounts linking the detrimental effect of prenatal maternal stress in early pregnancy on birth outcomes (McLean et al., 1995), we find a consistent increase in the probability of delivering premature and LBW children for mothers exposed to the bombing in their second trimester of gestation ${ }^{14}$. Additional analyses indicate that the effect of the exposure on LBW is explained by gestational age, since when we add a control for pre-term birth, the effect of the bombing disappears ${ }^{15}$.

[Table 2 about here] 
Our second research question is whether the terrorist attack had a heterogeneous effect according to parental SES. In Figure 2 we present the DID estimators for prematurity and LBW across the three trimesters of pregnancy and separately for high, medium and low SES. In general, we find the largest increase in both the risk of prematurity and LBW for children from medium and, particularly, low-SES mothers exposed to the bombing in the second trimester of pregnancy.

Figure 2 shows a 1.9 and 2.6 percentage point increase in the risk of prematurity among the children of medium and low-SES mothers, respectively. For LBW the effect of being pregnant in Madrid at the time the terrorist attack is similar, with a 1.8 and 1.9 percentage points increase. For the offspring of high-SES mother there is almost no effect of the treatment neither for prematurity nor for LBW. The shock associated with the Madrid bombing in 2004 thus seems to have predominantly affected low-SES mothers (and to a lesser degree medium-SES mothers), while sparing the high-SES mothers.

[Figure 2 about here]

\section{Parallel trend assumption and sensitivity analyses}

To evaluate the robustness of our results, here we present a set of tests: i) we assess the plausibility of the parallel trend assumption; ii) we perform a sensitivity analyses with placebo treatments; iii) we examine changes in the population composition between control and treatment groups; iv) we discuss the possible role of the elections in affecting our results ; v) we also restrict the analysis only to native women that are geographically less mobile than non-native ones (L. Q. Liu, 2018) and find consistent results.

First, since the causal effect of interest is estimated using a difference-in-differences design, it is important to assess the plausibility of the parallel trend assumption, which implies that the difference in pregnancy outcomes between Madrid and the control group would have been constant 
over time in the absence of treatment (Dimick \& Ryan, 2014). To this end, we estimate a model as in equation (4) in which we split the time periods $\left(t_{k}\right)$ into 20 trimesters, as specified in Table 1. Each time interval is then compared with the initial trimester $\mathrm{t} 1$ in 2000 . Figure 3 presents the predicted probability in prematurity (first graph) and LBW (second graph) in the Madrid province and the outcome-specific synthetic control province across 20 trimesters. In general, we do not find any notable deviation between the treatment and control group in any of the pre-exposure trimester. For both prematurity and LBW, the pre-treatment trends appear reasonably parallel for both outcomes. This result supports the internal validity of our DID estimator.

[Figure 3 about here]

As a second sensitivity analysis, we generate a non-parametric placebo permutation test similar to Chetty, Looney, and Kroft (2009). This test generates the empirical cumulative distribution of 676 placebo permutations of DID estimators using only the pre-treatment time points $\left(t_{1}-t_{13}\right.$ in Table 1). The permutations are obtained by estimating the model in equation (4) 13 times (one for each of the pre-treatment time points comprised between $t_{1}$ and $t_{13}$ of Table 1) for each of the 52 provinces $g_{k}$. For each of these models, $t_{k}$ (which varies from $t_{1}$ to $t_{13}$ ) is compared with all the other $t$ points collapsed together; each province $g_{k}$ is compared with the average of all the other provinces. In this test, we expect to find our estimates for Madrid in the top of the cumulative placebo distribution, i.e. larger in size than the effects that we find with the placebo test permutation.

In Figure 4 we present the results of the 676 placebo permutations. The left-hand graph shows the cumulative distribution of placebos for prematurity, while the right-hand graph shows the same for LBW. The dashed line is the treatment effect for the exposed in the second trimester estimated in model 1 and model 2 of Table 2. The solid line indicates the treatment effect for the exposed in the second trimester among low-SES, as shown in Figure 2. Both estimates are at the top of the placebo 
distributions, supporting the idea that the treatment effect in Madrid show an unusual increase in preterm and LBW deliveries that cannot be attributed to chance.

[Figure 4 about here]

We have also addressed potential issues of population composition changes. A reasonable concern about DID is that the treatment does not affect birth outcomes, but it changes population characteristics that in turn may account for the observed effect (Dunning, 2012). We inspected whether various demographic characteristics of mothers changed across time, among those: whether the mother is high or low-SES, is unmarried, and whether the mother is non-Spanish. For none of these demographic characteristics we observe neither an effect in correspondence with exposure to the bombing in March 2004 nor differences across groups as the trends remain parallel (Figure 5).

[Figure 5 about here]

A final issue refers to the role played by the national elections that took place 3 days after the bombings. An alternative explanation of our findings may be that the observed spikes in prematurity and LBW among low-SES mothers were determined by the results of the elections that took place after the terrorist attack. A recent study found that upset wins (the unexpected victory of an underdog in a competition) in a major sport event as the Super Bowl are associated with an increase in LBW deliveries, particularly among low-SES mothers (Duncan et al., 2017). The victory of the Spanish Socialist Party in the elections after the bombings was a largely unexpected outcome (Montalvo 2011). To test his alternative explanation, we have analyzed pre-electoral survey data and found that in the 2004 election low-SES supported the socialist party PSOE equally both in Madrid and the other Spanish provinces ${ }^{16}$. Thus, if the positive emotional cues associated with the unexpected electoral 
victory of the Spanish PSOE party were the driver of the spike in the risk of prematurity and LBW among low-SES pregnant women, we should observe similar results on birth outcomes of low SES women in all Spain and not exclusively in Madrid. Based on this evidence we can disregard the argument that the electoral results and the un-expected Socialist win explains the spike in LBW among low SES pregnant women in Madrid at the time of the terrorist attack.

\section{Mechanisms: the heterogeneous effects of the Madrid bombings}

In order to investigate the four mechanisms (different exposure, different sensitivity, selective survival, and parental response) that might explain why the effect is concentrated among low-SES parents we rely on findings of previous research and on information from external data sources.

\section{Different Exposure}

We know that exposure to a traumatic event increases stress and fosters mental health problems (Galea et al., 2002; Miguel-Tobal et al., 2006; North et al., 1999). Hence, if low-SES individuals were more likely to use the commuter trains, them, their friends, and their relatives - who by homophily may be more likely to also be low-SES - would be also those more likely to suffer from the stress generated by the attacks. To check the plausibility of this explanation, we investigate the socioeconomic composition of train users and reconstruct the information on the $\operatorname{SES}^{17}$ of the 193 individuals who died in the attacks ${ }^{18}$. In Table A2.5 in Online Appendix 2 we compare the incidence of the individuals who died in the attacks by SES and the overall SES distribution in the province of Madrid. We do not find an over-representation of low-SES individuals among those died in the attacks. Assuming that the same distribution by SES is found among over the 2,000 injured and victims, this suggests that the heterogeneity in the effects by parental education cannot be attributed to differential exposure and processes of diffusion of stress and fear through networks. 


\section{Selective Survival}

Selective survival could account for the heterogeneous effect we found, if high-SES mothers' pregnancies that should have been ended in a pre-term or LBW delivery had instead become miscarriages. Selective survival would then be confirmed if we find a drop in the number of conceptions, especially among the high-SES mothers exposed to the bombing when pregnant. To test the plausibility of this explanation, we compute the number of conceptions for each SES-subgroup across provinces and month of conception. Then we compute three regression models with the DID estimator defined as in equation (4), each having as outcome the SES-specific number of conceptions. We compare the exposed trimesters with children born before the attack, and the children conceived in the Madrid province (treated) with those conceived in a synthetic control province ${ }^{19}$. In Table 3 below, we report the DID estimate for the number of conceptions. Given that we do not find any decline in the number of conceptions in the exposed trimesters for any of the SES groups, we can exclude selective survival as a possible explanation for the SES-heterogeneity.

[Table 3 about here]

\section{Parental behaviors}

Another possible channel through which the exposure to the terrorist attack may have affected birth outcomes heterogeneously is by different parental behaviors of high-SES and low-SES families. A previous study, for instance, attributed heterogeneity in the effect of violence exposure on pregnancy outcomes to prenatal care access (Torche \& Villarreal, 2014). We doubt that difference in care access may explain the heterogenous effect we find in the context of the Madrid bombings, for several reasons. First, a possible reason of reduced antenatal care access is that public transport interrupted in Madrid, and this interruption may limit access to prenatal care (Evans \& Lien, 2005), especially among low-SES mothers that may have less access to private means of transport. However, as we 
argued in a previous section, public transport in Madrid never stopped ${ }^{20}$, making this scenario highly unlikely. Second, even if mothers were afraid to move in the days subsequent the attacks, or highSES accessed more care in comparison to low-SES mothers, a few antenatal care visits lost or gained seem not to have a large impact on pregnancy outcomes (Evans \& Lien, 2005; Persson \& RossinSlater, 2018; Sikorski, Wilson, Clement, Das, \& Smeeton, 1996). Third, there is also little evidence that exposure to violence may affect antenatal care access. Brown (2018) finds that exposure to a very extreme stressor such as cartel violence lasting over three years did not reduce the number of prenatal care visits taken by mothers.

On the contrary, stress induced behaviors such as smoking, or alcohol drinking might have a role in explaining our results. Suggestively, a recent study showed that in utero exposure to ETA attacks in Spain affected pregnancy outcomes. The authors argued that this effect was driven by smoking, as they found that being exposed to the attacks is positively associated with being a smoker among women in childbearing age (Quintana-Domeque \& Ródenas-Serrano, 2017). Despite other works did not find any evidence of this response to stress (Brown, 2018; Persson \& Rossin-Slater, 2018), none of these studies investigated whether the response was socially stratified and focused on populations different from the Spanish one, making comparisons not straightforward. The study by Quintana-Domeque and Ródenas-Serrano (2017) has some striking resemblance with ours in term of context and stressor, and it may thus provide some suggestive evidence that supports this mechanism. Especially, since we know that low-SES mothers are more likely to be smokers in Spain (Delgado et al., 2012), and they may be more likely to also engage in unhealthy behaviors in order to cope with stress (Pampel et al., 2010)

\section{Differential sensitivity}

According to differential sensitivity argument, some groups in the population are more sensitive to the exposure to acute stress. There is indeed some evidence that acute stress and chronic stress alone 
can be coped relatively well, while the combination of two types of stress is particularly damaging (Filipović, Zlatković, Gass, \& Inta, 2013; Hammen, Kim, Eberhart, \& Brennan, 2009). Following this argument, we might speculate that the effect of the bombings was more detrimental for low-SES mothers because they are already under the strain of everyday chronic stress (Turner \& Avison, 2003). In other words, the acute stress associated with the terrorist attack might have interacted with the preexisting higher level of stress among low SES women to produce the observed negative pregnancy outcomes.

\section{Discussion and Conclusion}

The in utero period is a crucial developmental stage which has consequences that reverberate across the life course. In this article we investigated whether prenatal maternal stress affects two pregnancy outcomes: prematurity and low birth weight. We also examined whether there is socio-economic heterogeneity in the effects of prenatal stress. To answer these questions, we used a natural experiment and study the train bombings in Madrid in March 2004 as an exogenous source of stress for women who were pregnant at the time of the terrorist attack. For a number of reasons that we have discussed at length above, our natural experiment has higher credibility and plausibility of random occurrence (Dunning 2012), compared to other natural experiments used in previous research to identify the effects of stress on pregnancy outcomes.

Two main results emerged from our study. First, using a difference-in-differences estimation with a synthetic control we found an effect of prenatal maternal stress during pregnancy on both prematurity and LBW for children exposed to the bombing during the second trimester of gestation. Their risk of pre-term birth rises of 1.4 percentage points, from 6.7 per cent to 8.1 per cent, compared to the control group, and that of being LBW of 1.1 percentage points, from 4.6 per cent to $5.7 \%$ about a $20 \%$ increase in relative terms in both cases. These results are consistently robust across a large set of sensitivity analyses, with different synthetic control group specifications and placebo tests. 
In general, our estimates are larger than those found from comparable studies based on causal designs. For instance, the effect of an upset win in the Super Bowl led to a 0.36 percentage points increase in LBW for lower educated mothers (Duncan et al., 2017), the Northridge Earthquake induced a 0.33 percentage points increase in LBW (Kim et al., 2017), while the effect of increased smoking taxation caused a 0.3 percentage points increase in LBW (Lien \& Evans, 2005). However, our estimates are slightly smaller than those obtained by Torche (2011) in relation to the Tarapaca earthquake in Chile, which increased LBW and prematurity of about 1.7 and 2.6 percentage points, respectively. This difference could be due to various reasons. First, it could be that the earthquake in Chile generated a higher level of stress in pregnant women and thus produced more severe consequences on birth outcomes for exposed individuals. Second, the Spanish population may have been more resilient to the psychological consequences of this kind of events owing to the long history of internal political violence (López-Rousseau, 2005), leading to a conservative estimate of the effects. Third, it could be that the estimates obtained by using the earthquake as a natural experiment are inflated by additional changes brought by the event as injuries experienced by pregnant mothers, which might have affected birth outcomes over and above the insurgence of maternal stress.

Our second main finding was that the negative consequences of exposure to prenatal maternal stress are concentrated among the offspring of low-SES parents. Of the four possible channels we discussed, we were only able to formally test and reject the hypotheses of differential mortality and differential exposure to the bombings and its related process of diffusion of stress by SES. Parental responses to stress such as unhealthy maternal behaviors and different sensitivity remain as likely mechanisms underpinning our results.

Previous results on socio-economic heterogeneity of the exposure to prenatal maternal stress on pregnancy outcomes are more mixed. Our results resemble those found by Brown (2018) on the effect Mexico cartel violence escalation pregnancy outcome. He also finds that the effect is concentrated among low-SES and suggest that the effect may be related to the biology behind stress, 
by excluding other alternative mechanisms. Additionally, we also detected effects similar to the study of Duncan et al. (2017), which report a small negative effect on pregnancy outcomes of unexpected loss in the super bowl on low-SES mothers' offspring. Moreover, the authors also argue they find a small increase of unhealthy behaviors such as smoking and drinking.

However, our results are different from those presented in the study by Persson and RossinSlater (2018), which investigates the consequences of the loss of a relative on pregnancy outcomes and does not find any heterogeneity, being both high- and low-SES mothers' children equally affected by the stressor. The authors also argue that the effect is solely driven by the biology of stress, as they can exclude a large set of other pathways (i.e. maternal behaviors, reaction to stress, and income shocks). It may be then possible that our results differ due to the different nature of the stressor. The loss of a relative is such a direct and proximate shock that hardly anyone, independently from the socio-economic background, may be able shelter him or herself by the pain and the stress, whereas the stress generated by a terrorist attack may be an event from which mothers may be able to take actions to protect themselves. Overall, it seems that our study aligns with research that uses distal events (i.e. violence, sport events) as a source of prenatal maternal stress.

The external validity of our results has also to be considered critically. As discussed in other articles investigating exogenous prenatal maternal stress (i.e. Torche, 2011; Torche \& Shwed, 2015), we identified the effect of an acute stressor on pregnancy outcomes, whereas mothers in their everyday lives may be more generally exposed to chronic stress (McEwen \& McEwen, 2017). In that respect the most substantively relevant finding of our study was that the negative effect of the acute stressor is concentrated among low-SES women. We suggested two possible mechanisms underlying these findings. While with the available data we are not able to differentiate between parental responses and differential selectivity, both mechanisms point to processes of cumulative disadvantage where acute stress interacts with chronic stress or the effect acute stress intensify unhealth behaviors. Indeed there is evidence both from psychology and neuroscience that it is the combination of acute 
and chronic stress to be highly detrimental in major depression and in neuronal injury (Filipović et al., 2013; Hammen et al., 2009). The important and general implication of our findings is that higher exposure to chronic stress and more common unhealth habits make low-SES pregnant women also more vulnerable to the exposure to acute stressful events, with negative consequences for their pregnancy outcomes.

To conclude, this article brings new and robust evidence on the effect of prenatal maternal stress on pregnancy outcomes and shows that the effect is mostly concentrated among low-SES families. Further research should therefore more deeply investigate the mechanisms that contribute to the heterogeneity of the effect by parental SES, in particular parental response and different sensitivity to stress. In this way one would also address the critical question of how low-SES parents might transmit disadvantage to their children even when they are in the womb.

\section{Endnotes}

1. Source: https://cadenaser.com/ser/2004/03/12/espana/1079052611_850215.html?int=masinfo

2. The Madrid autonomous community population was: $5,205,408$ individuals in $2000 ; 5,372,433$ in 2001; $5,527,152$ in $2002 ; 5,718,942$ in $2003 ; 5,804,829$ in $2004 ; 5,964,143$ in 2005; and it reached more than 6 million in 2006. Source: https://www.ine.es/dynt3/inebase/en/index.htm?padre=523

3. Data on births are registered since 1975, and they are available at the following address: http://www.ine.es/dyngs/INEbase/en/operacion.htm?c=Estadistica_C\&cid=1254736177007\&menu=resultados $\& \operatorname{secc}=1254736195443 \& \mathrm{idp}=1254735573002$

4. There is not a specific nationwide regulation on whether the hospitals have to provide parents with detailed information on the delivery at the time of the dismission, some hospitals provide it and other do not. However, if there is a recall bias is usually upward (i.e. children are reported as heavier), and frail pre-term and low birth weight deliveries are usually well recalled (Juárez et al., 2012) 
5. The probability of having a missing value on LBW variable does not correlate with any demographic characteristics (gender, mother's age, parity, ethnicity, parental SES) nor with year of birth or the province of residence. The only exceptions are the oversea province of Melilla and mothers with missing information on SES (10\% of missing on LBW). Nonetheless, we exclude Melilla from the following analyses, and we explain the motivation of this choice in a following paragraph.

6. We cannot use parental education, since it is available in the registers only after 2006.

7. A justification for the threefold classification is provided in Table A2.2 in appendix 2 where we report the median income band of each occupational category. The median income for the major group 5 (Sales and services elementary occupations) is lower than median income of group 4 and similar to those of group 6 and 7. The median income band are obtained from CIS (2006).

8. Descriptive statistics are reported in table A2.2 in Online Appendix 2.

9. In addition to not having missing value, we selected the province as geographical unit for the following reasons. First, it would be difficult to distinguish whether a municipality was exposed more or less within the province of Madrid; hence we try to assess the average effect within the whole province. Second, if mothers exposed to the bombing decided after the attack to spend their pregnancy and give birth outside the city of Madrid, we are likely to include them in our treatment variable. Third, this is a conservative choice, because if the terrorist attack had also some negative consequences on other provinces closer to Madrid, we would provide a conservative estimate of the true causal effect of maternal stress induced by the bombings. Fourth, it also allows to include births in the city of Alcalá de Henares, the place from which three out of four trains involved in the bombing started their journey.

10. We repeated the analyses by assuming the $1^{\text {st }}$ of the month, and the results do not change.

11. We excluded Ceuta and Melilla due to the high number of missing values in Melilla.

12. We computed the same analyses using a three-way interaction, and the results do not change. We present the results from the separated models as they do not constrain the effects of the control variables to be the same for the three SES groups, unlike the pooled model with the three-way interaction.

13. Hypothetically, the statistical significance may refer to a super-population, which can be imagined as an infinite population from which this specific population has been drawn (Berk, 2004). In another vein, a 
significance test may be meaningful if we consider possible measurement errors in the data generating process or errors in the model specifications (Babones, 2013).

14. The unadjusted non-parametric DID estimates also confirm these patterns. We find an effect of exposure to the attack on LBW and prematurity that is consistently larger for the second trimester with an increase in the respective probabilities of 1.2 and 1.4 percentage point (Appendix Table A2.4).

15. Results available upon request

16. In January 2004, low-SES in Madrid and in the rest of the Spanish provinces did not differ in their evaluation of the leader of the PSOE. The evaluation was measured in a scale from 0 (very bad) to 10 (very good). Moreover, the share of low-SES reporting a positive opinion (>6) for PSOE leader Zapatero was about $41 \%$ both in Madrid in the rest of Spain (CIS, 2004).

17. We reconstructed the occupations of the causalities from the obituaries that are available online at the following link: http://www.elmundo.es/documentos/2004/03/espana/atentados $11 \mathrm{~m} / \mathrm{victimas} . h$ tml. We recoded these occupations into the classification of occupations (roughly an ISCO 68 at 1 digit with 12 categories) available in the birth registers we use. Detailed data on coding of occupations are available upon request.

18. It is reasonable to believe that those who died were representative of the people who would take the trains, as being on a carriage where a bomb exploded was most likely random among the passengers.

19. We followed the same procedure we used in the main analyses to create the synthetic controls for the two pregnancy outcomes. The synthetic control is made of only of the province of Barcelona, and the synthetic control procedure assigns all the weights to this province independently from the matching strategy. We constructed this synthetic control in order to best resemble Madrid province in the pre-treatment number of conceptions and other covariates such as: share of births for each socio-economic group, average maternal age, and number of non-Spanish mothers. Analyses are computed by aggregating data, and each cell refers to a province in a specific month and year of conception.

20. Evans \& Lien (2005) found a negative effect of a bus strike on antenatal care access, but they investigated a 28-days long strike. In Madrid, as we reported in a previous section, the same day of the bombing substitute transportation took place. 


\section{References}

Abadie, A., Diamond, A., \& Hainmueller, J. (2010). Synthetic control methods for comparative case studies: Estimating the effect of California's tobacco control program. Journal of the American statistical Association, 105(490), 493-505.

Abadie, A., \& Gardeazabal, J. (2003). The economic costs of conflict: A case study of the Basque Country. American Economic Review, 93(1), 113-132.

Aizer, A., Stroud, L., \& Buka, S. (2016). Maternal Stress and Child Outcomes Evidence from Siblings. Journal of Human Resources, 51(3), 523-555. doi:10.3368/jhr.51.3.0914-6664R

Almond, D., Currie, J., \& Duque, V. (2017). Childhood circumstances and adult outcomes: Act II. NBER Working Paper 23017.

Almond, D., \& Mazumder, B. (2013). Fetal Origins and Parental Responses. In K. J. Arrow \& T. F. Bresnahan (Eds.), Annual Review of Economics, Vol 5 (Vol. 5, pp. 37-56). Palo Alto: Annual Reviews.

Babones, S. J. (2013). Methods for quantitative macro-comparative research: Sage Publications.

Becker, G. S., \& Rubinstein, Y. (2004). Fear and the response to terrorism: an economic analysis.

Becker, G. S., \& Tomes, N. (1976). Child endowments and the quantity and quality of children. Journal of Political Economy, 84(4, Part 2), S143-S162.

Behrman, J. R., Pollak, R. A., \& Taubman, P. (1982). Parental Preferences and Provision for Progeny. Journal of Political Economy, 90(1), 52-73. doi:10.1086/261039

Berk, R. A. (2004). Regression analysis: A constructive critique (Vol. 11): Sage.

Bernardi, F. (2014). Compensatory advantage as a mechanism of educational inequality: A regression discontinuity based on month of birth. Sociology of Education, 87(2), 74-88.

Bertrand, M., Duflo, E., \& Mullainathan, S. (2004). How much should we trust differences-indifferences estimates? The Quarterly journal of economics, 119(1), 249-275. 
Bharadwaj, P., Løken, K. V., \& Neilson, C. (2013). Early life health interventions and academic achievement. American Economic Review, 103(5), 1862-1891.

Black, S. E., Devereux, P. J., \& Salvanes, K. G. (2007). From the cradle to the labor market? The effect of birth weight on adult outcomes. Quarterly Journal of Economics, 122(1), 409-439. doi:10.1162/qjec.122.1.409

Black, S. E., Devereux, P. J., \& Salvanes, K. G. (2016). Does grief transfer across generations? bereavements during pregnancy and child outcomes. American Economic Journal: Applied Economics, 8(1), 193-223.

Brown, R. (2018). The Mexican drug war and early-life health: The impact of violent crime on birth outcomes. Demography, 55(1), 319-340.

Cebolla-Boado, H., \& Salazar, L. (2016). Differences in perinatal health between immigrant and native-origin children: Evidence from differentials in birth weight in Spain. Demographic Research, 35(7), 167-200.

Chetty, R., Looney, A., \& Kroft, K. (2009). Salience and taxation: Theory and evidence. American Economic Review, 99(4), 1145-1177.

CIS. (2004). Preelectoral Elecciones Generales 2004. Survery $n r .2555$.

CIS. (2006). CLASES SOCIALES Y ESTRUCTURA SOCIAL. Survery nr. 2634.

Conley, D. (2008). Bringing sibling differences in: Enlarging our understanding of the transmission of advantage in families. Social class: How does it work, 179-200.

Conley, D., \& Bennett, N. G. (2000). Is biology destiny? Birth weight and life chances. American Sociological Review, 458-467.

Conley, D., \& Bennett, N. G. (2001). Birth weight and income: interactions across generations. Journal of Health and Social Behavior, 450-465.

Currie, J., \& Rossin-Slater, M. (2013). Weathering the storm: Hurricanes and birth outcomes. Journal of health economics, 32(3), 487-503. 
Currie, J., \& Schwandt, H. (2013). Within-mother analysis of seasonal patterns in health at birth. Proceedings of the National Academy of Sciences, 110(30), 12265-12270.

Currie, J., \& Schwandt, H. (2015). The 9/11 Dust Cloud and Pregnancy Outcomes: A Reconsideration. Journal of Human Resources.

de La Rochebrochard, E., \& Thonneau, P. (2002). Paternal age and maternal age are risk factors for miscarriage; results of a multicentre European study. Human Reproduction, 17(6), 1649-1656.

Delgado, Y. P., Rodríguez, G. M., Samper, M. V., Caballero, V. P., Cuadrón, L. A., Alvarez, M. S., . . Olivares, J. L. (2012). Socio-cultural, obstetric and anthropometric characteristics of newborn children of mothers who smoke in Spain. Paper presented at the Anales de pediatria (Barcelona, Spain: 2003).

Dickerson, S. S., \& Kemeny, M. E. (2004). Acute stressors and cortisol responses: a theoretical integration and synthesis of laboratory research. Psychological bulletin, 130(3), 355.

Dimick, J. B., \& Ryan, A. M. (2014). Methods for evaluating changes in health care policy: the difference-in-differences approach. Jama, 312(22), 2401-2402.

Duncan, B., Mansour, H., \& Rees, D. I. (2017). It's Just a Game The Super Bowl and Low Birth Weight. Journal of Human Resources, 52(4), 946-978.

Dunkel Schetter, C. (2011). Psychological science on pregnancy: stress processes, biopsychosocial models, and emerging research issues. Annual review of psychology, 62, 531-558.

Dunning, T. (2012). Natural experiments in the social sciences: a design-based approach: Cambridge University Press.

Eskenazi, B., Marks, A. R., Catalano, R., Bruckner, T., \& Toniolo, P. G. (2007). Low birthweight in New York City and upstate New York following the events of September 11th. Human Reproduction, 22(11), 3013-3020.

Evans, W. N., \& Lien, D. S. (2005). The benefits of prenatal care: evidence from the PAT bus strike. Journal of Econometrics, 125(1-2), 207-239. 
Feder, A., Nestler, E. J., \& Charney, D. S. (2009). Psychobiology and molecular genetics of resilience. Nature Reviews Neuroscience, 10(6), 446.

Ferman, B., Pinto, C., \& Possebom, V. (2017). Cherry picking with synthetic controls.

Filipović, D., Zlatković, J., Gass, P., \& Inta, D. (2013). The differential effects of acute vs. chronic stress and their combination on hippocampal parvalbumin and inducible heat shock protein 70 expression. Neuroscience, $236,47-54$.

Galea, S., Ahern, J., Resnick, H., Kilpatrick, D., Bucuvalas, M., Gold, J., \& Vlahov, D. (2002). Psychological sequelae of the September 11 terrorist attacks in New York City. New England Journal of Medicine, 346(13), 982-987.

Goisis, A., Remes, H., Barclay, K., Martikainen, P., \& Myrskylä, M. (2017). Advanced maternal age and the risk of low birth weight and preterm delivery: a within-family analysis using Finnish population registers. American Journal of Epidemiology, 186(11), 1219-1226.

Grätz, M., \& Torche, F. (2016). Compensation or Reinforcement? The Stratification of Parental Responses to Children's Early Ability. Demography, 53(6), 1883-1904.

Hammen, C., Kim, E. Y., Eberhart, N. K., \& Brennan, P. A. (2009). Chronic and acute stress and the prediction of major depression in women. Depression and anxiety, 26(8), 718-723.

Härkönen, J., Kaymakçalan, H., Mäki, P., \& Taanila, A. (2012). Prenatal health, educational attainment, and intergenerational inequality: the Northern Finland Birth Cohort 1966 Study. Demography, 49(2), 525-552.

Heckman, J. J. (2007). The economics, technology, and neuroscience of human capability formation. Proceedings of the National Academy of Sciences of the United States of America, 104(33), 13250-13255. doi:10.1073/pnas.0701362104

Hobel, C. J., Goldstein, A., \& Barrett, E. S. (2008). Psychosocial stress and pregnancy outcome. Clinical obstetrics and gynecology, 51(2), 333-348. 
Holzman, C., Jetton, J., Siler-Khodr, T., Fisher, R., \& Rip, T. (2001). Second trimester corticotropinreleasing hormone levels in relation to preterm delivery and ethnicity. Obstetrics \& Gynecology, 97(5), 657-663.

Hsin, A., \& Felfe, C. (2014). When does time matter? Maternal employment, children's time with parents, and child development. Demography, 51(5), 1867.

Jordán, J., \& Horsburgh, N. (2006). Spain and Islamist terrorism: Analysis of the threat and response 1995-2005. Mediterranean Politics, 11(2), 209-229.

Juárez, S., Alonso Ortíz, T., Ramiro-Fariñas, D., \& Bolúmar, F. (2012). The quality of vital statistics for studying perinatal health: the Spanish case. Paediatric and perinatal epidemiology, 26(4), 310-315.

Kaul, A., Klößner, S., Pfeifer, G., \& Schieler, M. (2015). Synthetic control methods: Never use all pre-intervention outcomes together with covariates.

Kim, B., Carruthers, C. K., \& Harris, M. C. (2017). Maternal stress and birth outcomes: Evidence from the 1994 Northridge earthquake. Journal of Economic Behavior \& Organization, 140, 354-373.

Kiserud, T., Piaggio, G., Carroli, G., Widmer, M., Carvalho, J., Jensen, L. N., . . Talegawkar, S. A. (2017). The World Health Organization fetal growth charts: a multinational longitudinal study of ultrasound biometric measurements and estimated fetal weight. PLoS medicine, 14(1), e1002220.

Lien, D. S., \& Evans, W. N. (2005). Estimating the impact of large cigarette tax hikes the case of maternal smoking and infant birth weight. Journal of Human Resources, 40(2), 373-392.

Liu, E. M., Liu, J.-T., \& Tseng, T.-Y. H. (2015). The Impact of a Natural Disaster on the Incidence of Fetal Losses and Pregnancy Outcomes. Draft, July.

Liu, L. Q. (2018). Regional Labor Mobility in Spain: International Monetary Fund. 
López-Rousseau, A. (2005). Avoiding the death risk of avoiding a dread risk: The aftermath of March 11 in Spain. Psychological Science, 16(6), 426-428.

Mancuso, R. A., Schetter, C. D., Rini, C. M., Roesch, S. C., \& Hobel, C. J. (2004). Maternal prenatal anxiety and corticotropin-releasing hormone associated with timing of delivery. Psychosomatic Medicine, 66(5), 762-769. doi:10.1097/01.psy.0000138284.70670.d5

McEwen, C. A., \& McEwen, B. S. (2017). Social Structure, Adversity, Toxic Stress, and Intergenerational Poverty: An Early Childhood Model. Annual Review of Sociology(0).

McLean, M., Bisits, A., Davies, J., Woods, R., Lowry, P., \& Smith, R. (1995). A placental clock controlling the length of human pregnancy. Nature medicine, 1(5), 460-463.

McPherson, M., Smith-Lovin, L., \& Cook, J. M. (2001). Birds of a feather: Homophily in social networks. Annual Review of Sociology, 27(1), 415-444.

Miguel-Tobal, J. J., Cano-Vindel, A., Gonzalez-Ordi, H., Iruarrizaga, I., Rudenstine, S., Vlahov, D., \& Galea, S. (2006). PTSD and depression after the Madrid March 11 train bombings. Journal of Traumatic Stress, 19(1), 69-80. doi:10.1002/jts.20091

Montalvo, J. G. (2011). Voting after the bombings: A natural experiment on the effect of terrorist attacks on democratic elections. Review of Economics and Statistics, 93(4), 1146-1154.

North, C. S., Nixon, S. J., Shariat, S., Mallonee, S., McMillen, J. C., Spitznagel, E. L., \& Smith, E. M. (1999). Psychiatric disorders among survivors of the Oklahoma City bombing. Jama, 282(8), 755-762.

Pampel, F. C., Krueger, P. M., \& Denney, J. T. (2010). Socioeconomic disparities in health behaviors. Annual Review of Sociology, 36, 349.

Persson, P., \& Rossin-Slater, M. (2018). Family ruptures, stress, and the mental health of the next generation. American Economic Review, 108(4-5), 1214-1252. 
Quintana-Domeque, C., \& Ródenas-Serrano, P. (2017). The hidden costs of terrorism: The effects on health at birth. Journal of health economics, 56, 47-60. doi:https://doi.org/10.1016/j.jhealeco.2017.08.006

Schlenger, W. E., Caddell, J. M., Ebert, L., Jordan, B. K., Rourke, K. M., Wilson, D., . . Kulka, R. A. (2002). Psychological reactions to terrorist attacks: findings from the National Study of Americans' Reactions to September 11. Jama, 288(5), 581-588.

Sherrieb, K., \& Norris, F. H. (2013). Public health consequences of terrorism on maternal-child health in New York City and Madrid. Journal of urban health, 90(3), 369-387.

Sikorski, J., Wilson, J., Clement, S., Das, S., \& Smeeton, N. (1996). A randomised controlled trial comparing two schedules of antenatal visits: the antenatal care project. Bmj, 312(7030), 546553.

Torche, F. (2011). The effect of maternal stress on birth outcomes: exploiting a natural experiment. Demography, 48(4), 1473-1491.

Torche, F. (2018). Prenatal Exposure to an Acute Stressor and Children's Cognitive Outcomes. Demography, 55(5), 1611-1639. doi:10.1007/s13524-018-0700-9

Torche, F., \& Sirois, C. (2018). Restrictive Immigration Law and Birth Outcomes of Immigrant Women. American Journal of Epidemiology, 188(1), 24-33.

Torche, F., \& Villarreal, A. (2014). Prenatal exposure to violence and birth weight in Mexico selectivity, exposure, and behavioral responses. American Sociological Review, 79(5), 966992.

Turner, R. J., \& Avison, W. R. (2003). Status variations in stress exposure: Implications for the interpretation of research on race, socioeconomic status, and gender. Journal of Health and Social Behavior, 488-505. 
Tables

Table 1 Time points definition by year and trimester of conception

\begin{tabular}{|c|c|c|c|c|c|}
\hline \multirow{3}{*}{ Conceived between } & \multicolumn{5}{|c|}{ Years } \\
\hline & 2000 & 2001 & 2002 & 2003 & 2004 \\
\hline & (1) & (2) & (3) & (4) & (5) \\
\hline March/May & $\mathrm{t} 1^{\mathrm{c}}$ & $\mathrm{t} 5$ & t9 & $\mathrm{t} 13$ & $\mathrm{t} 17$ \\
\hline June/August & $\mathrm{t} 2$ & t6 & $\mathrm{t} 10$ & $3^{\text {rd }}$ Trim. $^{b}$ & $\mathrm{t} 18$ \\
\hline Sept./Nov. & $\mathrm{t} 3$ & $\mathrm{t} 7$ & $\mathrm{t} 11$ & $2^{\text {nd }}$ Trim. $^{b}$ & $\mathrm{t} 19$ \\
\hline Dec./Feb. ${ }^{a}$ & $\mathrm{t} 4^{\mathrm{a}}$ & $\mathrm{t} 8^{\mathrm{a}}$ & $\mathrm{t} 12^{\mathrm{a}}$ & $1^{\text {st }}$ Trim. $^{\text {ba }}$ & $\mathrm{t} 20^{\mathrm{a}}$ \\
\hline
\end{tabular}


Table 2 LPMs predicting the probability of LBW and prematurity: DID estimates of exposure to the Madrid train bombings.

\begin{tabular}{|c|c|c|}
\hline & $\begin{array}{c}\text { Prematurity } \\
\text { Model } 1\end{array}$ & $\begin{array}{c}\text { LBW } \\
\text { Model } 2\end{array}$ \\
\hline & $\begin{array}{l}\text { Beta } \\
(\mathrm{SE})\end{array}$ & $\begin{array}{l}\text { Beta } \\
\text { (SE) }\end{array}$ \\
\hline Third Trimester * MP & $\begin{array}{c}0.003 \\
(0.002)\end{array}$ & $\begin{array}{l}0.005^{*} \\
(0.001)\end{array}$ \\
\hline Second Trimester * MP & $\begin{array}{c}0.014 * * * \\
(0.001)\end{array}$ & $\begin{array}{c}0.011 * * \\
(0.001)\end{array}$ \\
\hline First Trimester * MP & $\begin{array}{c}0.005 \\
(0.004)\end{array}$ & $\begin{array}{c}0.001 \\
(0.002)\end{array}$ \\
\hline Intercept & $\begin{array}{c}0.067 * * * \\
(0.002)\end{array}$ & $\begin{array}{c}0.046^{* * * *} \\
(0.001)\end{array}$ \\
\hline $\mathrm{N}$ & $1,711,085$ & 448,914 \\
\hline
\end{tabular}

Note: Standard errors clustered at the provincial level. Significance levels: $*<0.05 ; * *<0.01 ; * * *<0.001$. In both models the control group is a synthetic control province specific for each outcome. Synthetic control is defined as weights at the provincial level. MP=Madrid Province. Model are adjusted for: maternal age $(<19,20 / 29,30 / 34,35+)$; parental SES (high, medium, low, inactive, no information); parity $\left(1^{\text {st }} / 2^{\text {nd }}, 3^{\text {rd }} / 4^{\text {th }},>4^{\text {th }}\right.$ born $)$; maternal marital status; Spanish native/non-native; sex of the child. 
Table 3 DID estimates of the effect of Madrid Bombing on the number of conceptions.

\begin{tabular}{|c|c|c|c|}
\hline & High SES & Medium SES & Low SES \\
\hline & $\begin{array}{l}\text { Beta } \\
(\mathrm{SE})\end{array}$ & $\begin{array}{l}\text { Beta } \\
(\mathrm{SE})\end{array}$ & $\begin{array}{l}\text { Beta } \\
(\mathrm{SE})\end{array}$ \\
\hline \multirow[t]{2}{*}{ Third Trimester $*$ MP } & 0.110 & 0.035 & $0.032 *$ \\
\hline & $(0.012)$ & $(0.010)$ & $(0.002)$ \\
\hline \multirow[t]{2}{*}{ Second Trimester * MP } & 0.039 & 0.023 & 0.038 \\
\hline & $(0.007)$ & $(0.008)$ & $(0.006)$ \\
\hline \multirow[t]{2}{*}{ First Trimester $*$ MP } & $0.053 *$ & 0.028 & 0.034 \\
\hline & $(0.004)$ & $(0.002)$ & $(0.004)$ \\
\hline \multirow[t]{2}{*}{ Conceived After * MP } & -0.036 & $-0.050 * *$ & -0.039 \\
\hline & $(0.006)$ & $(0.001)$ & $(0.003)$ \\
\hline $\mathrm{N}$ & 124 & 124 & 124 \\
\hline
\end{tabular}

Note: Standard error clustered at the provincial level. Significance levels: $*<0.05 ; * *<0.01 ; * * *<0.001$. Number of conceptions are per 1,000. MP=Madrid Province. DID estimates are computed respect to the children born before the attack. Geographical control generated by synthetic control, and it consists of the sole province of Barcelona. Models include fixed effects for: month of conception, year of conception, month-year of conception. Models also account for number of non-Spanish mothers and average maternal age. 


\section{Figures}

Figure 1 DAG illustrating the causal pathways between bombing and birth outcomes

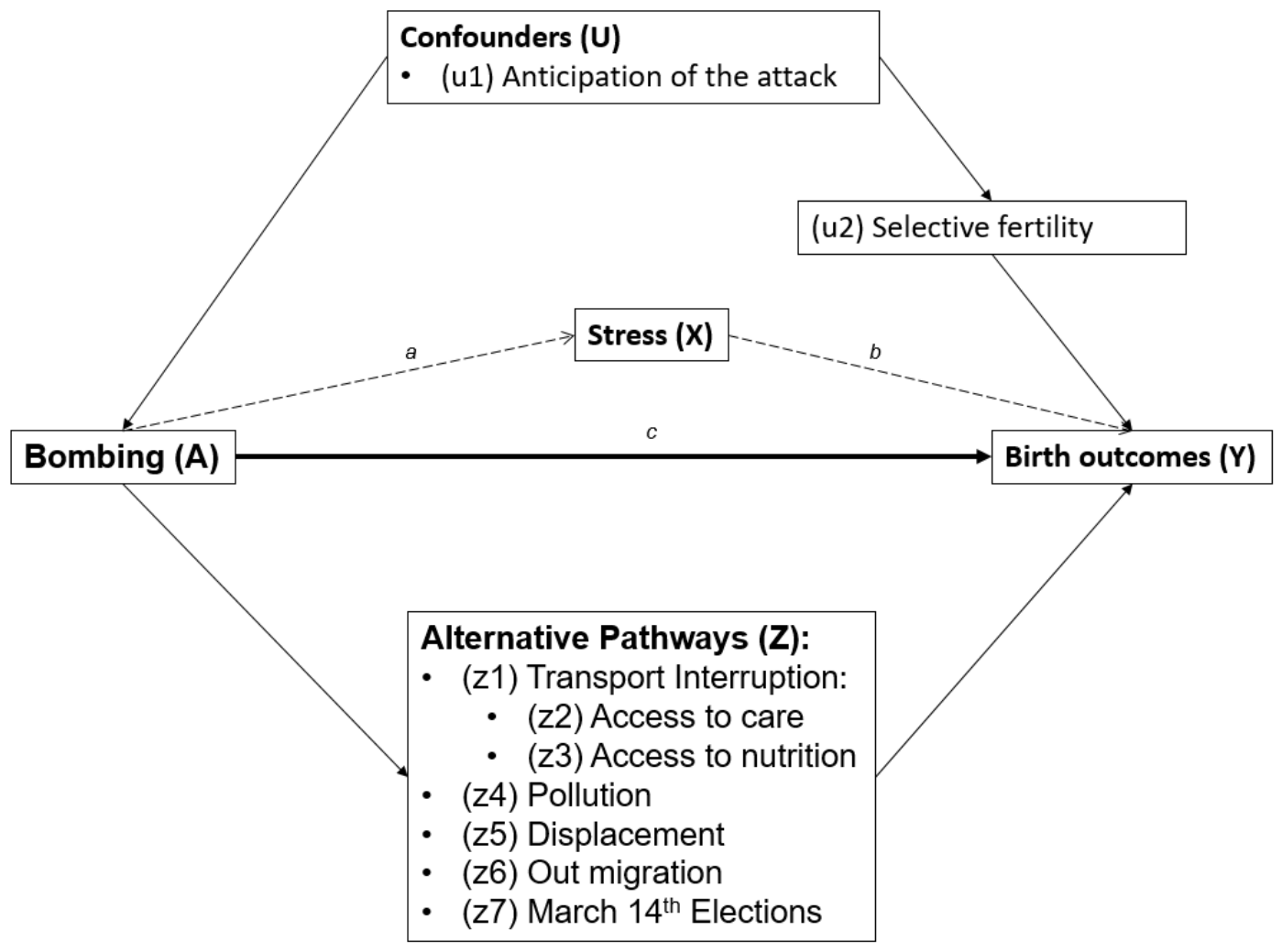


Figure 2 DID estimates and 95\% confidence intervals of exposure to the Madrid train bombings on prematurity (first row) and LBW (second row) for the three exposed trimesters by SES.
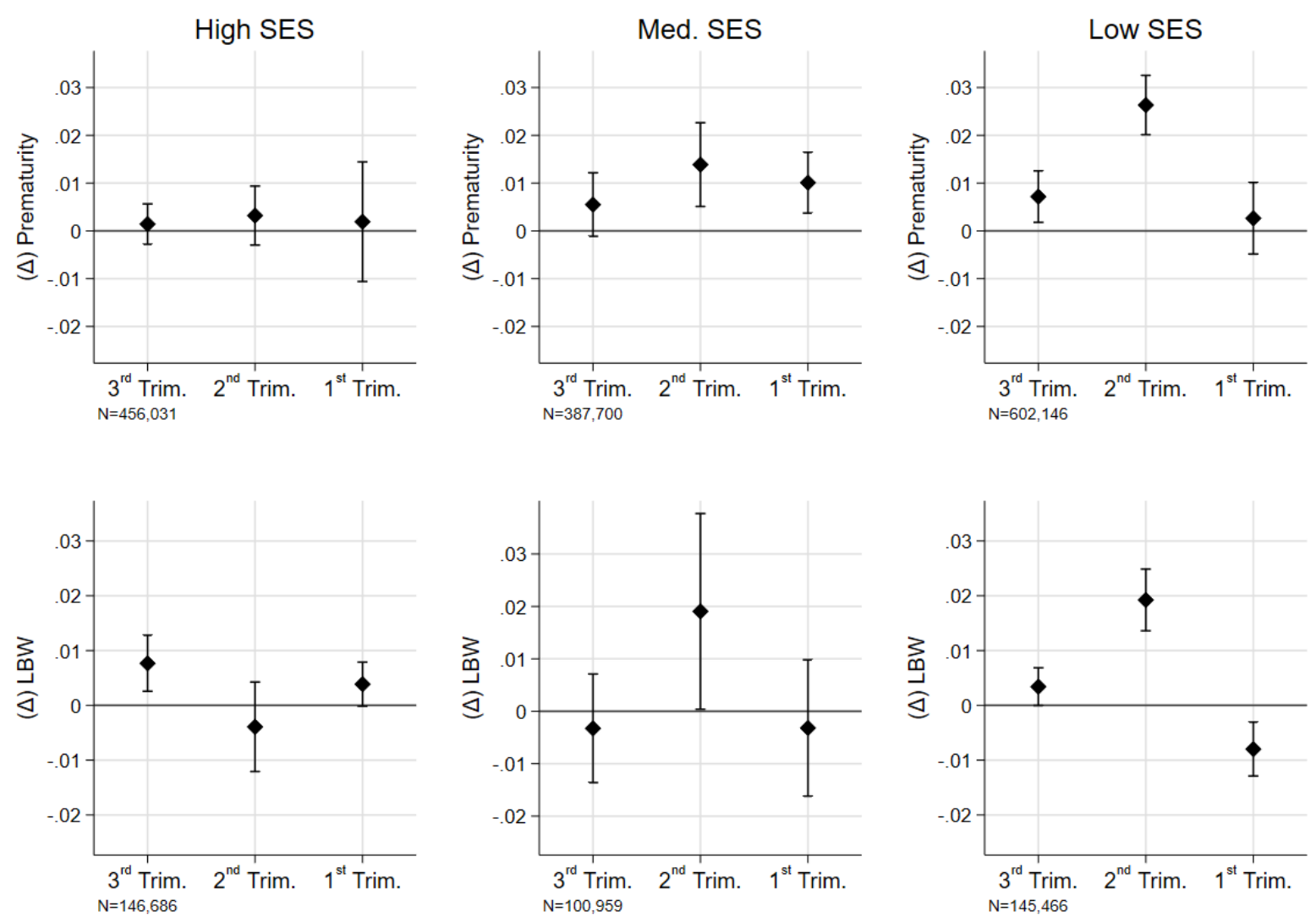

\begin{abstract}
Note: the reference category is the difference among children born before $(t b b)$ the attack in the treated and the SESspecific synthetic control province. The point estimate is the DID estimator of equation (4). Standard errors are clustered at the provincial level. All the models include year and month of conception fixed effects. Other control variables are: age of the mother at birth; mother's marital status; whether the mother is not Spanish; sex of the newborn; parity.
\end{abstract}


Figure 3 Predicted probabilities (and 95\% confidence intervals) of prematurity (upper panel) and LBW (lower panel) across treatment group and synthetic control province. Children conceived between January 2000 and February 2005. Time points defined as in Table 1.
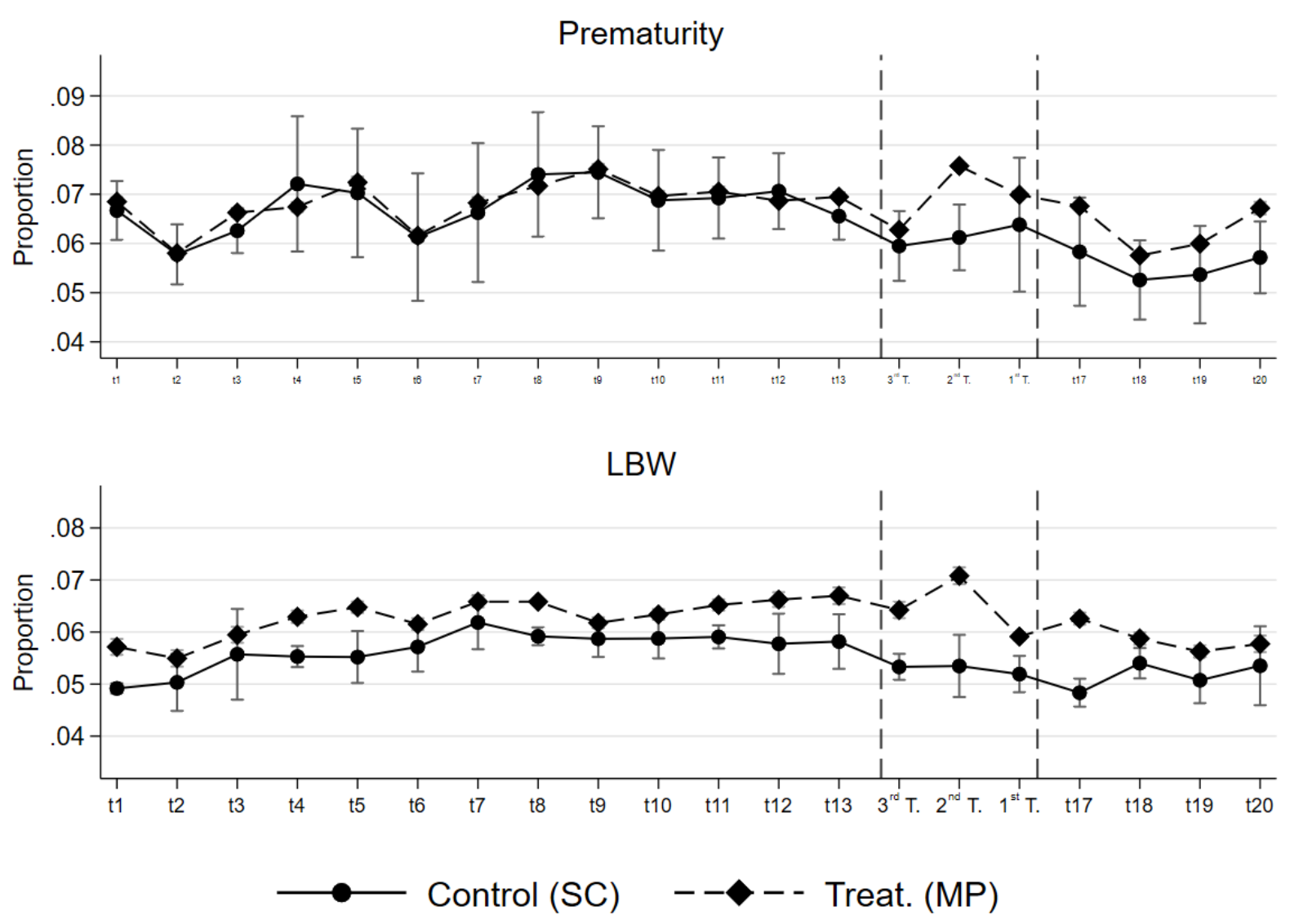

\footnotetext{
Note: The figure shows the trends in the two outcome variables. Each panel is estimated from a linear probability model defined as in equation (4): with $t_{k}$ having as many time points as defined in Table 1 . Standard errors clustered at the provincial level. Vertical dashed lines indicate the time of the bombing. The points at $3^{\text {rd }} \mathrm{T}$., $2^{\text {nd }} \mathrm{T}$., and $1^{\text {st }} \mathrm{T}$. refer to the children who were in the womb at the time of the bombing.
} 
Figure 4 Robustness check: distribution of placebo permutation and our preferred estimates (vertical lines) of the Madrid bombings on prematurity (left graph) and LBW (right graph)
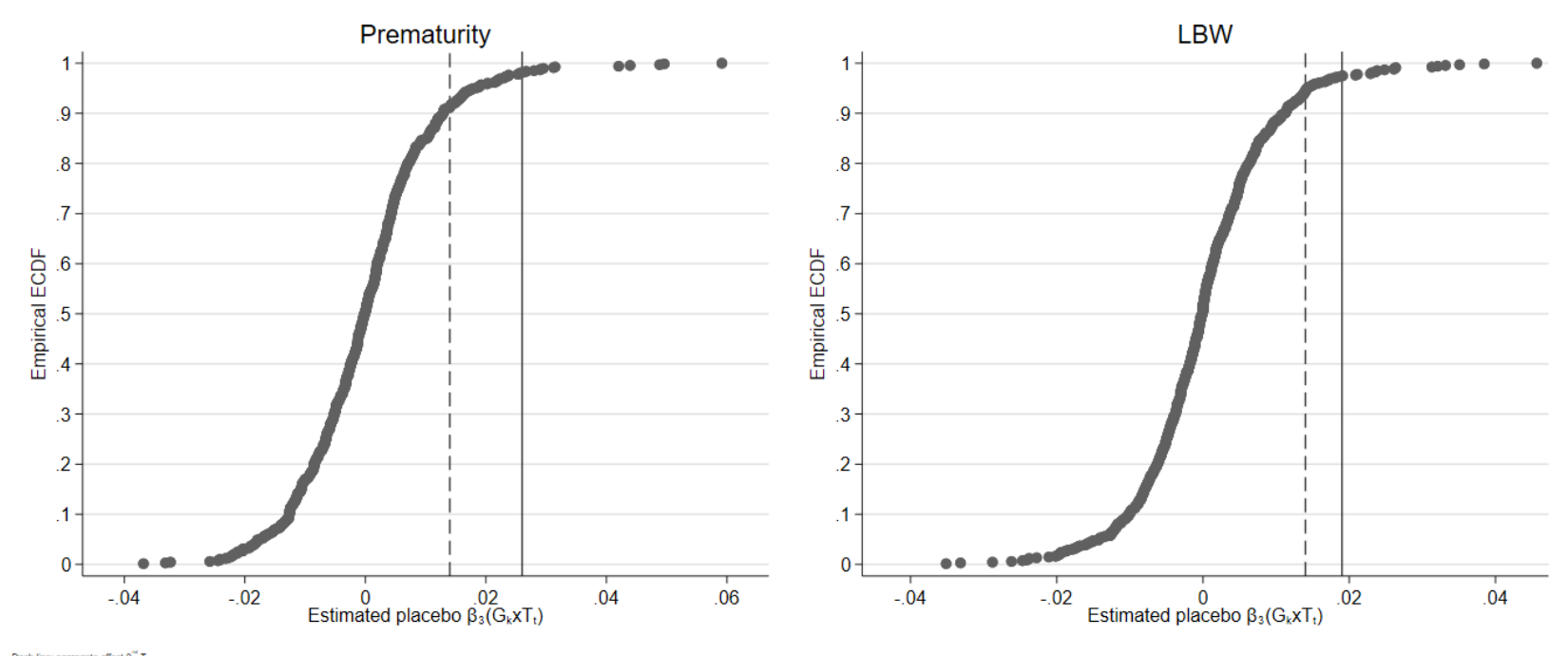

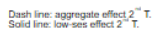

Note: These plots show the cumulative distribution of 676 placebo permutations. Dashed line is the estimate for the effect of the treatment for those exposed in the second trimester estimated in model 1 and model 2 of Table 2. Solid line is the effect of the treatment for those exposed in the second trimester among low-SES, as shown in Figure 1. 
Figure 5 Population characteristics over time in the province of Madrid (treatment) and synthetic control for LBW.
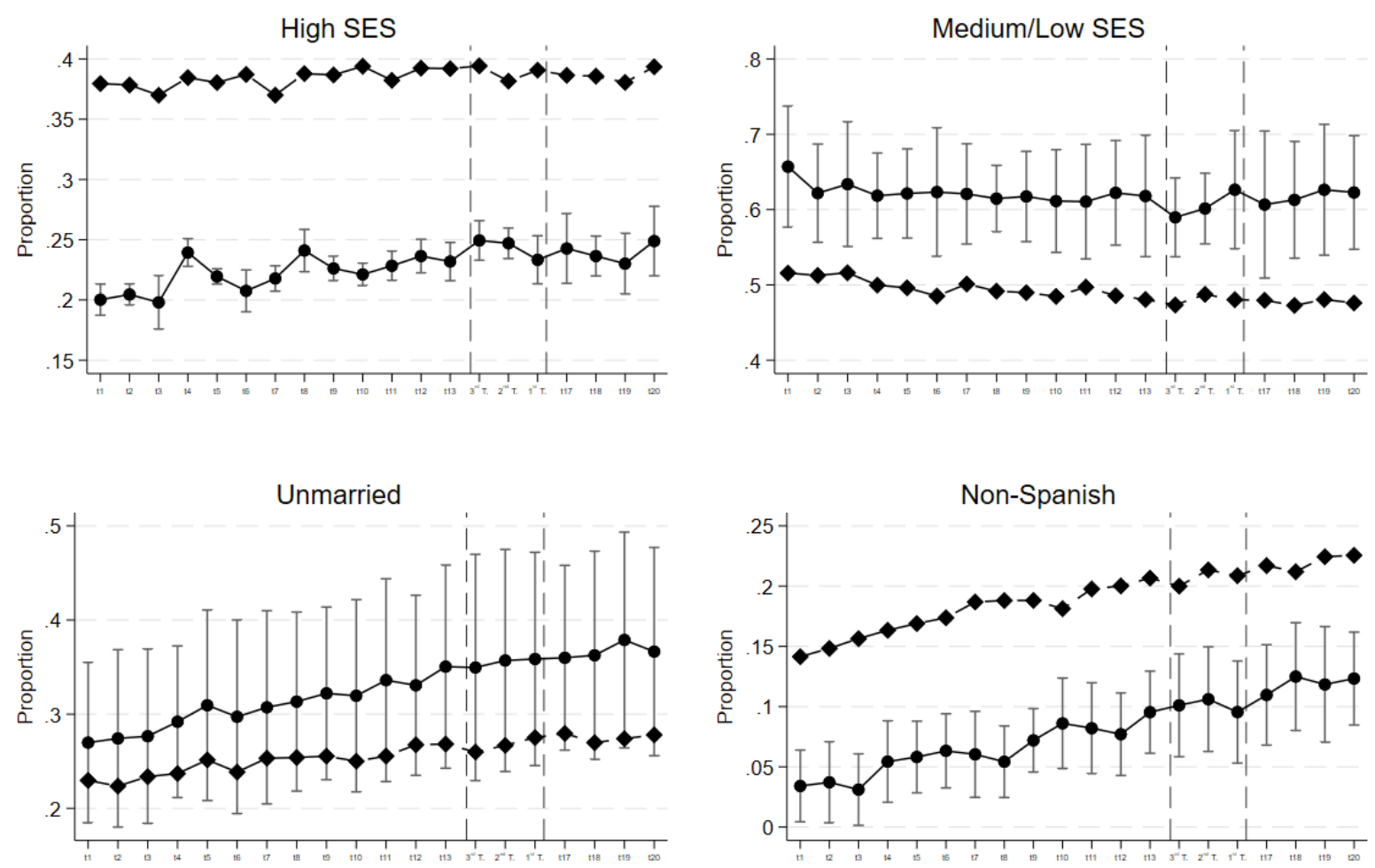

Control (SC) - - - - Treat. (MP)

Note: This figure is generated computing four LPMs with outcomes dummies taking value 1 if the delivery was from a high-SES (left-hand-upper-graph), low/medium-SES (right-hand-upper-graph), unmarried women (left-hand-lowergraph), non-Spanish mother (right-hand-lower-graph), and as a predictor the interaction term of equation (4) with $t_{k}$ defined as in Table 1. Control group is synthetic control province for LBW in the general analysis. 


\section{Online Appendix 1. Synthetic control \& sensitivity analyses}

Synthetic control weights

[Table A1.1 about here]

[Table A1.2 about here]

Sensitivity analyses

Given the importance of the control group in the context of DID, and the possible sources of bias in also defining the synthetic control, we provide sensitivity analyses using two different control groups: (1) average of the Spanish provinces excluding Madrid; (2) synthetic control provinces defined with only the average level of the outcome in the pre-treatment period as a predictor, with the weights reported in table A1.2 above, similarly to Torche and Sirois' (2018) strategy. It is worth noticing that we picked the average of the outcome in the pre-treatment period, but weights and results do not vary notably if we match on the value of the outcome in the trimester before the attack or any other pretreatment trimester.

Table A1.3 shows the results of four regression models specified as defined in eq. (4) in the article. The models use two different control groups. Results remain consistent across a different control group and a different synthetic control specification. In the general analyses the results are identical. In the analyses of heterogeneity by SES, low-SES consistently show the highest impact of the attack, whereas no effect is ever found among high-SES.

[Table A1.3 about here]

\section{References}

Torche, F., \& Sirois, C. (2018). Restrictive Immigration Law and Birth Outcomes of Immigrant Women. American Journal of Epidemiology, 188(1), 24-33. 


\section{Online Appendix 1 Tables}

Table A1.1 Synthetic control weights for each outcome and sub-group. synthetic control weights are generated by using all pre-treatment outcome as predictor.

\begin{tabular}{|c|c|c|}
\hline \multirow[t]{2}{*}{ Province } & \multicolumn{2}{|c|}{ Weights: all pre-treatment } \\
\hline & Prematurity & LBW \\
\hline Araba/Álava & 0.003 & 0 \\
\hline Albacete & 0.082 & 0 \\
\hline Alicante/Alacant & 0.005 & 0 \\
\hline Almería & 0.062 & 0 \\
\hline Ávila & 0.139 & 0.027 \\
\hline Badajoz & 0.003 & 0 \\
\hline Balears, Illes & 0.007 & 0 \\
\hline Barcelona & 0.003 & 0 \\
\hline Burgos & 0.093 & 0 \\
\hline Cáceres & 0.003 & 0 \\
\hline Cádiz & 0.007 & 0 \\
\hline Castellón/Castelló & 0.086 & 0 \\
\hline Ciudad Real & 0.005 & 0 \\
\hline Córdoba & 0.008 & 0 \\
\hline Coruña, A & 0.002 & 0 \\
\hline Cuenca & 0.004 & 0 \\
\hline Girona & 0.003 & 0.086 \\
\hline Granada & 0.013 & 0.132 \\
\hline Guadalajara & 0.004 & 0 \\
\hline Gipuzkoa & 0.004 & 0 \\
\hline Huelva & 0.087 & 0 \\
\hline Huesca & 0.003 & 0 \\
\hline Jaén & 0.002 & 0 \\
\hline León & 0.008 & 0 \\
\hline Lleida & 0.006 & 0.18 \\
\hline Rioja, La & 0.003 & 0 \\
\hline Lugo & 0.04 & 0 \\
\hline Málaga & 0.006 & 0 \\
\hline Murcia & 0.088 & 0 \\
\hline Navarra & 0.004 & 0 \\
\hline Ourense & 0.004 & 0.056 \\
\hline Asturias & 0.063 & 0.029 \\
\hline Palencia & 0.005 & 0 \\
\hline Palmas, Las & 0.009 & 0.408 \\
\hline Pontevedra & 0.004 & 0 \\
\hline Salamanca & 0.003 & 0 \\
\hline S.C. de Tenerife & 0.009 & 0.042 \\
\hline Cantabria & 0.002 & 0 \\
\hline Segovia & 0.002 & 0 \\
\hline Sevilla & 0.007 & 0 \\
\hline Soria & 0.065 & 0 \\
\hline Tarragona & 0.003 & 0 \\
\hline Teruel & 0.004 & 0 \\
\hline Toledo & 0.004 & 0 \\
\hline Valencia/València & 0.013 & 0 \\
\hline Valladolid & 0.005 & 0.041 \\
\hline Bizkaia & 0.003 & 0 \\
\hline Zamora & 0.007 & 0 \\
\hline Zaragoza & 0.005 & 0 \\
\hline
\end{tabular}


Table A1.2 Synthetic control weights for each outcome and sub-group. synthetic control weights are generated by using only the pre-treatment average of the outcome as predictor.

\begin{tabular}{|c|c|c|}
\hline \multirow[t]{2}{*}{ Province } & \multicolumn{2}{|c|}{ Weights: average pre-treatment outcomes } \\
\hline & Prem & LBW \\
\hline Araba/Álava & 0 & 0 \\
\hline Albacete & 0 & 0 \\
\hline Alicante/Alacant & 0 & 0 \\
\hline Almería & 0 & 0 \\
\hline Ávila & 0 & 0 \\
\hline Badajoz & 0 & 0 \\
\hline Balears, Illes & 0 & 0 \\
\hline Barcelona & 0.518 & 0.565 \\
\hline Burgos & 0 & 0 \\
\hline Cáceres & 0 & 0 \\
\hline Cádiz & 0 & 0 \\
\hline Castellón/Castelló & 0 & 0 \\
\hline Ciudad Real & 0 & 0 \\
\hline Córdoba & 0 & 0 \\
\hline Coruña, A & 0 & 0 \\
\hline Cuenca & 0 & 0 \\
\hline Girona & 0 & 0 \\
\hline Granada & 0 & 0 \\
\hline Guadalajara & 0 & 0 \\
\hline Gipuzkoa & 0 & 0 \\
\hline Huelva & 0 & 0 \\
\hline Huesca & 0 & 0 \\
\hline Jaén & 0 & 0 \\
\hline León & 0.456 & 0 \\
\hline Lleida & 0 & 0 \\
\hline Rioja, La & 0 & 0 \\
\hline Lugo & 0 & 0 \\
\hline Málaga & 0 & 0 \\
\hline Murcia & 0 & 0 \\
\hline Navarra & 0 & 0 \\
\hline Ourense & 0 & 0 \\
\hline Asturias & 0 & 0.408 \\
\hline Palencia & 0 & 0 \\
\hline Palmas, Las & 0 & 0 \\
\hline Pontevedra & 0 & 0 \\
\hline Salamanca & 0 & 0 \\
\hline S.C. de Tenerife & 0 & 0.027 \\
\hline Cantabria & 0 & 0 \\
\hline Segovia & 0 & 0 \\
\hline Sevilla & 0.026 & 0 \\
\hline Soria & 0 & 0 \\
\hline Tarragona & 0 & 0 \\
\hline Teruel & 0 & 0 \\
\hline Toledo & 0 & 0 \\
\hline Valencia/València & 0 & 0 \\
\hline Valladolid & 0 & 0 \\
\hline Bizkaia & 0 & 0 \\
\hline Zamora & 0 & 0 \\
\hline Zaragoza & 0 & 0 \\
\hline
\end{tabular}


Table A1.3 LPMS as specified in eq. (4). Different control groups. Standard errors clustered at the provincial level.

\begin{tabular}{|c|c|c|c|c|}
\hline \multirow[t]{2}{*}{ Control: } & \multicolumn{2}{|c|}{ Aggregate of Spanish provinces } & \multicolumn{2}{|c|}{$\begin{array}{c}\text { Synthetic Control } \\
\text { AVG pre-T. Outcome }\end{array}$} \\
\hline & M1 & M2 & M3 & M4 \\
\hline Pregnancy outcome: & $\begin{array}{c}\text { LBW } \\
\text { Beta (SE) }\end{array}$ & $\begin{array}{c}\text { Prem. } \\
\text { Beta (SE) }\end{array}$ & $\begin{array}{c}\text { LBW } \\
\text { Beta (SE) }\end{array}$ & $\begin{array}{c}\text { Prem. } \\
\text { Beta (SE) }\end{array}$ \\
\hline \multicolumn{5}{|l|}{ General } \\
\hline 3 T. x MP & $\begin{array}{c}0.000 \\
(0.001)\end{array}$ & $\begin{array}{c}0.003 \\
(0.002)\end{array}$ & $\begin{array}{c}-0.001 \\
(0.001)\end{array}$ & $\begin{array}{l}0.002^{*} \\
(0.000)\end{array}$ \\
\hline 2 T. x MP & $\begin{array}{c}0.006 * * * \\
(0.001)\end{array}$ & $\begin{array}{c}0.013 * * * \\
(0.002)\end{array}$ & $\begin{array}{l}0.007 * \\
(0.001)\end{array}$ & $\begin{array}{c}0.010 * * * \\
(0.001)\end{array}$ \\
\hline $1 \mathrm{~T} . \mathrm{x} \mathrm{MP}$ & $\begin{array}{c}0.001 \\
(0.001)\end{array}$ & $\begin{array}{c}0.007 \\
(0.002)\end{array}$ & $\begin{array}{l}-0.003 \\
(0.002)\end{array}$ & $\begin{array}{l}0.005 \dagger \\
(0.001)\end{array}$ \\
\hline $\mathrm{N}$ & $1,639,122$ & $1,720,739$ & 506,013 & 569,821 \\
\hline \multicolumn{5}{|l|}{ High SES } \\
\hline 3 T. x MP & $\begin{array}{c}0.000 \\
(0.002)\end{array}$ & $\begin{array}{c}0.001 \\
(0.002)\end{array}$ & $\begin{array}{l}-0.002 \\
(0.003)\end{array}$ & $\begin{array}{l}-0.004 \\
(0.001)\end{array}$ \\
\hline 2 T. x MP & $\begin{array}{l}-0.001 \\
(0.001)\end{array}$ & $\begin{array}{c}0.004 \\
(0.002)\end{array}$ & $\begin{array}{c}0.000 \\
(0.001)\end{array}$ & $\begin{array}{c}0.003 \\
(0.001)\end{array}$ \\
\hline 1 T. $x$ MP & $\begin{array}{c}0.002 \\
(0.001)\end{array}$ & $\begin{array}{l}0.006 * * \\
(0.002)\end{array}$ & $\begin{array}{c}0.002 \\
(0.001)\end{array}$ & $\begin{array}{l}0.009 * * \\
(0.000)\end{array}$ \\
\hline $\mathrm{N}$ & 448,105 & 436,221 & 202,486 & 202,762 \\
\hline \multicolumn{5}{|l|}{ Medium SES } \\
\hline 3 T. x MP & $\begin{array}{l}-0.004 * \\
(0.002)\end{array}$ & $\begin{array}{c}0.002 \\
(0.002)\end{array}$ & $\begin{array}{l}-0.002 \\
(0.002)\end{array}$ & $\begin{array}{l}0.009 * \\
(0.002)\end{array}$ \\
\hline 2 T. $x$ MP & $\begin{array}{c}0.011 * * * \\
(0.001)\end{array}$ & $\begin{array}{c}0.016 * * * \\
(0.002)\end{array}$ & $\begin{array}{c}0.014 * * \\
(0.000)\end{array}$ & $\begin{array}{l}0.014 * \\
(0.004)\end{array}$ \\
\hline 1 T. $x$ MP & $\begin{array}{c}-0.004 \dagger \\
(0.002)\end{array}$ & $\begin{array}{l}0.008^{*} \\
(0.003)\end{array}$ & $\begin{array}{l}-0.013 \\
(0.004)\end{array}$ & $\begin{array}{c}0.001 \\
(0.001)\end{array}$ \\
\hline $\mathrm{N}$ & 379,950 & 389,751 & 115,359 & 118,225 \\
\hline Low SES & & & & \\
\hline 3 T. x MP & $\begin{array}{c}0.001 \\
(0.001)\end{array}$ & $\begin{array}{c}0.011^{* * *} * \\
(0.003)\end{array}$ & $\begin{array}{l}-0.004 \\
(0.004)\end{array}$ & $\begin{array}{c}0.010 * * \\
(0.002)\end{array}$ \\
\hline 2 T. x MP & $\begin{array}{c}0.011 * * * \\
(0.001)\end{array}$ & $\begin{array}{c}0.021 * * * \\
(0.002)\end{array}$ & $\begin{array}{l}0.011^{*} \\
(0.004)\end{array}$ & $\begin{array}{c}0.015 * * * \\
(0.001)\end{array}$ \\
\hline 1 T. $x$ MP & $\begin{array}{c}-0.005 * * \\
(0.001)\end{array}$ & $\begin{array}{c}0.005 * * * \\
(0.003)\end{array}$ & $\begin{array}{c}-0.008 * * * \\
(0.001)\end{array}$ & $\begin{array}{l}0.005 \dagger \\
(0.002)\end{array}$ \\
\hline $\mathrm{N}$ & 581,889 & 606,100 & 144,336 & 167,675 \\
\hline
\end{tabular}




\section{Online Appendix 2. Supplementary Tables}

Table A2.1 Distribution of gestational age in weeks missing among parental SES in the population (row percentages)

\begin{tabular}{lcccccc}
\hline & \multicolumn{6}{c}{ Parental SES } \\
\cline { 2 - 7 } Prematurity & High & Medium & Low & Inactive & No Info/Army & Total \\
& & & $\%(\mathrm{~N})$ & & & $\mathrm{N}$ \\
\hline$>$ 37th (0) & 28.16 & 23.62 & 34.97 & 3.05 & 10.2 & $1,794,251$ \\
<37th (1) & 23.93 & 22.29 & 38.65 & 3.93 & 11.19 & 123,305 \\
Missing (.) & 17.51 & 16.94 & 32.5 & 3.86 & 29.18 & 253,547 \\
Total & 26.68 & 22.77 & 34.89 & 3.19 & 12.47 & $2,171,103$ \\
& $(579,220)$ & $(494,321)$ & $(728,856)$ & $(65,637)$ & $(270,772)$ & \\
\hline
\end{tabular}


Table A2.2 Distribution of LBW missing among family SES in the population (row percentages)

\begin{tabular}{lcccccc}
\hline & \multicolumn{7}{c}{ Parental SES } \\
\cline { 2 - 7 } LBW & High & Medium & Low & Inactive & No Info/Army & Total \\
$\%(\mathrm{~N})$ & & & $\mathrm{N}$ \\
\hline$>2500(0)$ & 27.71 & 23.37 & 34.96 & 3.08 & 10.89 & $1,953,127$ \\
$<2500(1)$ & 23.04 & 22.11 & 38.67 & 3.83 & 12.36 & 115,789 \\
Missing (.) & 11.18 & 12.00 & 29.30 & 4.65 & 42.87 & 102,187 \\
Total & 26.68 & 22.70 & 34.89 & 3.19 & 12.47 & $2,171,103$ \\
& $(579,220)$ & $(494,321)$ & $(757,511)$ & $(69,279)$ & $(270,772)$ & \\
\hline
\end{tabular}


Table A2.3 Median Income band by occupational class

\begin{tabular}{cc}
\hline ISCO 68 & Median \\
Birth Registers & Income \\
& Band \\
& (ISCO 68) \\
\hline
\end{tabular}

MAJOR GROUP 1: Professionals, technicians and associate professional

(Profesionales, tecnicos y trabajadores asimilados)

MAJOR GROUP 2: Manager and legislators

(Personal directivo de la administracion publica y de las empresas)

MAJOR GROUP 3: Clerical support workers

(Personal administrativo y personal asimilado)

MAJOR GROUP 4: Salesman and shop owners

(Comerciantes y vendedores)

MAJOR GROUP 5: Sales and services elementary occupations

(Personas de los servicios)

MAJOR GROUP 6: Agricultural, forestry and fishery workers

(Agricultores, ganaderos, arboricultores, pescadores y cazadores)

MAJOR GROUP 7: Production workers, trade workers, plant and machine operators

(Trabajadores de la produccion y asimilados, conductores de equipos, de transportes y peones (no agrarios))

Note: Income band (monthly income - EURO): 1) No income; 2) < 300 Euro; 3) 301/601; 4) 901/1200;

5) $1201 / 1800$; 6) 1801/2400; 7) 2401/3000; 8) 3001/4500; 9) 4500/6000; 10) 6000+ 
Table A2.4 Descriptive statistics by treatment and rest of Spain

\begin{tabular}{lccc}
\hline & Treated & & \\
\cline { 2 - 2 } $\begin{array}{lcc}\text { Madrid } \\
\%\end{array}$ & & $\begin{array}{c}\text { Rest of Spain } \\
\%\end{array}$ \\
\hline Prematurity & 6.71 & & 6.13 \\
LBW & 6.14 & & 5.5 \\
Female (child) & 48.40 & & 48.43 \\
& & & \\
Parental SES & & & \\
High & 38.79 & & 24.52 \\
Medium & 23.16 & & 22.70 \\
Low & 25.65 & & 36.54 \\
Inactive & 1.58 & & 3.48 \\
No Info & 10.83 & & 12.76 \\
& & \\
Parity & & \\
First or Second Child & 55.85 & & 56.27 \\
Third or Fourth & 41.75 & & 41.52 \\
More than Fourth & 2.40 & & 2.21 \\
& & \\
Maternal Age & & \\
<19 & 1.74 & \\
20/29 & 28.97 & 2.42 \\
30/34 & 40.92 & 38.28 \\
35+ & 28.37 & 24.44 \\
Unmarried & & \\
Non-Spanish & 25.24 & \\
\hline & 18.46 & \\
\hline
\end{tabular}


Table A2.5 Unadjusted non-parametric DID estimates (Madrid vs. synthetic control province)

LBW Prematurity

\begin{tabular}{lcc}
\hline Time & & \\
$3^{\text {rd }}$ Trim. & 0.43 & 0.22 \\
$2^{\text {nd }}$ Trim. & 1.2 & 1.39 \\
$1^{\text {st }}$ Trim. & 0.02 & 0.56 \\
\hline
\end{tabular}


Table A2.6 SES of the deceased in the attack and Madrid occupational structure

\begin{tabular}{lcc}
\hline & $\begin{array}{c}\text { Deceased in the } \\
\text { attack SES }\end{array}$ & $\begin{array}{c}\text { ISCO 68 (Madrid) } \\
\text { CIS- 2634 }\end{array}$ \\
\hline High SES & $(\%)$ & $(\%)$ \\
\cline { 2 - 3 } Low/Medium SES & 24.5 & 66.7 \\
Inactive/ No Info/Army & 59.9 & 13.4 \\
\hline
\end{tabular}

